\title{
A Stronger Versus Weaker Walker: Understanding Model Differences in Fast and Slow Tropical Pacific Responses to Global Warming
}

Ulla K. Heede ( $\square$ ulla.heede@yale.edu )

Yale University https://orcid.org/0000-0002-3241-0552

Alexey V. Fedorov

Yale University

Natalie J. Burls

George Mason University

\section{Research Article}

Keywords: Versus Weaker, Tropical Pacific, transient ocean thermostat

Posted Date: March 18th, 2021

DOI: https://doi.org/10.21203/rs.3.rs-306140/v1

License: (c) (i) This work is licensed under a Creative Commons Attribution 4.0 International License.

Read Full License 


\section{Abstract}

The tropical Pacific response to radiative forcing remains uncertain as projected future changes to the Walker circulation and SST patterns vary substantially among climate models. Here, we study what sets the magnitude and timescales of the response and why they differ across models. Specifically, we compare the fast and slow responses of the tropical Pacific to abrupt $\mathrm{CO}_{2}$ increases $\left(2,4,8,16 \times \mathrm{xO}_{2}\right)$ in two configurations of the same model family (CESM) that differ in horizontal resolution and mean biases. We find that the model with a higher resolution shows a transient ocean thermostat-like response to $\mathrm{CO}_{2}$ forcing, with a stronger Walker cell and lack of warming in the eastern Pacific trade wind belts. This fast response lasts for about 50 years and is followed by a slight Walker cell weakening and equatorial warming. The second model, with a coarser resolution, shows a weak and short-lasting ocean thermostat response, followed by pronounced Walker cell weakening and eastern equatorial Pacific warming, similar to the long-term pattern noted in previous studies. These fast and slow responses also manifest in gradual $\mathrm{CO}_{2}$ increase experiments. We relate the magnitude of the fast ocean-thermostat response to the structure of the equatorial thermocline, setting the strength of the Bjerknes feedback. The magnitude and timing of the eastern equatorial Pacific warming are, is turn, related to the competition of the windevaporation-SST feedback amplifying the ocean-thermostat against the slowdown of oceanic subtropical cells and extra-tropical warming eroding the thermostat. Different balances between these effects could explain the large spread in the future projections for the tropical Pacific.

\section{Introduction}

The mean zonal structure of the tropical Pacific climate system is maintained by coupled oceanatmosphere interactions that depend on the Bjerknes feedback (Bjerknes, 1969), connecting the surface winds of the Walker circulation and the zonal SST gradient along the equator (Neelin and Dijkstra 1995, F.F. Jin 1996, Lui and Huang 1997). In turn, the mean state of the tropical Pacific controls a variety of climate phenomena including interannual fluctuations associated with ENSO (Dijkstra and Neelin, 1995; Jin, 1996; Fedorov and Philander, 2000; Collins et al., 2010; DiNezio et al., 2012) and variations in global ocean heat uptake on decadal timescales scales (Kosaka and Xie, 2013; England et al., 2014; Hu and Fedorov, 2017). Understanding how the zonal mean structure of the tropical Pacific will change with global warming has direct implications for society on a range of scales (Pierrehumbert, 2000; Griffiths et al., 2005; Ashok and Yamagata, 2009; McPhaden, Santoso and Cai, 2020), yet a robust understanding of its response to atmospheric radiative forcing remains elusive due to uncertainties associated with the key mechanisms controlling changes to the tropical Pacific mean state (DiNezio et al., 2012; Cai et al., 2015), pervasive model biases (Burls and Fedorov, 2014) and discrepancies between the models and the observations. Thus, gaining a fundamental and robust understanding of how the tropical Pacific will change (or has changed in the past) is a crucial challenge for climate sciences, and one of the goals of the present paper is to compare and contrast such changes in a suite of simulations with abrupt and gradual $\mathrm{CO}_{2}$ increases within two different models albeit of the same GCM family (CESM, see Model setup). 
Predicting robust changes to the zonal structure of the tropical Pacific using state-of-the-art global climate models has proven challenging, both for historical simulations and projections for the $21^{\text {st }}$ century. Kociuba and Power (2015) and Coats and Karnauskas (2017), among other studies, have shown that the models of the Coupled Model Intercomparison Project, phase 5 (CMIP5) are unable to capture the decadal strengthening of the Walker circulation of the past 3 decades described in multiple studies (Meng et al., 2012; Tokinaga et al., 2012; England et al., 2014; Ma and Zhou, 2016; Zhang et al., 2019). Overall, the majority of GCMs, but not all, predict an eastern equatorial Pacific warming pattern developing over the $21^{\text {st }}$ century and the corresponding weakening of the Walker circulation (e.g. DiNezio et al., 2009; Xie et al.,2010; Ying et al.,2016), but the magnitude of this pattern and the Walker cell weakening vary strongly across models. Consequently, Plesca et al. (2018) questioned the robustness of weakening of the Walker circulation in CMIP5 future projections because of the large spread of simulated trends. These findings suggest that in order to achieve robust GCM projections for the future tropical climate, we need to understand what causes the large spread among CMIP models, as well as why they are unable to capture the observed trend.

While the details of climate model projections of the tropical Pacific vary across models, progress has been made in understanding interactions between different components of the tropical climate system that are important for the response of the tropical Pacific to global warming. In a series of papers, Clement et al. (1996), Cane et al. (1997). and Seager and Murtugudde (1997). proposed that the equatorial Pacific east-west SST gradient could increase in response to $\mathrm{CO}_{2}$ due to enhanced warming of surface waters in the western Pacific contrasted by continuous upwelling of cold water in the east. Seager et al. (2019). modified the ocean thermostat mechanism to include wind strengthening off the equator due to evaporative cooling in the trade wind belts and the related wind-evaporation-SST (WES) feedback. Conflicting the thermostat argument, Held \& Soden, (2006), Vecchi et al., (2006) and Vecchi \& Soden (2007) argued that the Walker circulation should weaken as a result of the reduced vertical mass flux in the tropical circulation; the latter reduction should occur as specific humidity increases at faster rates in a warming atmosphere than precipitation. In addition, enhanced evaporative cooling over the warm pool has been also proposed as a mechanism that reduces warming in the western tropical Pacific (Knutson and Manabe, 1995; Merlis and Schneider, 2011) and thus weakens the Walker cell by reducing the zonal SST gradient. Other studies focused on the role of shallow meridional overturning circulation, arguing that the temperature of water upwelled in the eastern Pacific is ultimately controlled by the temperature of extra-tropical source waters and the intensity of the ocean subtropical cells - STCs (McCreary Jr and Lu, 1994; Gu and Philander, 1997; Seager and Murtugudde, 1997; Burls and Fedorov, 2014). These mechanisms were dubbed 'the ocean tunnel'.

More recently, these diverging theories have been investigated, and reconciled to some extent, in a range of studies using a hierarchy of model experiments in (- Heede et al.,2020). These authors used idealized experiments with box models and comprehensive GCM simulations to show that the ocean thermostat (OT) and the eastern equatorial Pacific warming (EP)/Walker circulation weakening are both robust responses to $\mathrm{CO}_{2}$ forcing in the fully coupled tropical Pacific ocean-atmosphere system, depending on the 
timescales considered. Their simulations exhibited a transient response first, characterized by an IndoPacific thermostat with stronger equatorial winds over the Pacific ocean, and warming over the Maritime continent and the Indian Ocean (a modified version of the original ocean thermostat mechanism proposed by Clement et al. 1996). This fast response closely resemble the observed trends in the IndoPacific between the 1990s and 2010s (Luo, Sasaki and Masumoto, 2012; Lee et al., 2015; Ma and Zhou, 2016; Hu and Fedorov, 2019). The importance of the dynamical ocean in driving the transient Pacific cooling in response to $\mathrm{CO}_{2}$ forcing has been also illustrated by Luo et al. (2017). Another important feature of the fast response is a westward shift of the Walker cell towards the Indian Ocean, which was not considered in Clement et al. (1996). The link between Indian Ocean warming and Pacific cooling is confirmed by Zhang et al. (2019) who show that imposing the observed warming over the Indian Ocean in a GCM causes cooling over the equatorial Pacific, by shifting the Walker cell westward and strengthening central equatorial winds, creating an inter-basin warming contrast similar to the observed.

The fast OT-type response is eventually replaced by a slow, gradually evolving response characterized by weakening of the Walker circulation, and a corresponding eastern equatorial Pacific warming (EP). This EP warming pattern dominates the multi-model-mean GCM projections for the late $21^{\text {st }}$ century Pacific (DiNezio et al., 2009; Xie et al., 2010; Ying, Huang and Huang, 2016). To investigate the development of this pattern, Heede et al. (2020) have used one of the GCMs of the present study (T31, see methods) and compared simulations with and without a full dynamic ocean. They find that on longer timescales, this tropical Pacific response in this particular model is in large part driven by enhanced extra-tropical warming and the slowdown of the oceanic subtropical cells (STCs) in addition to stronger evaporative cooling of the western Pacific relative to the eastern Pacific. The respective roles of the tropics and extratropics in driving warming patterns over the Pacific is also investigated by Stuecker et al. (2020). Similarly, they find that extra-tropical warming is key for driving enhanced tropical warming by slowing down the Hadley cell as well as the oceanic subtropical cells, thereby reducing poleward heat transport. Kang_et al. (2020). similarly find in reversed experiments that the Walker cell strengthens in response to extra-tropical cooling for simulations including a dynamic ocean.

In addition to these ocean tunnel effects, Heede et al. (2020) also find that the weakening of the tropical atmospheric circulation implied by the thermodynamic scaling arguments of Held and Soden (2006) is indeed observed for the mid-troposphere vertical mass flux, but its surface manifestation is not robust across the experiments and ocean-atmosphere interactions appear to be more important in controlling the overall Walker cell and SST response in the tropical Indo-Pacific.

In summary, multiple studies indicate that the tropical Pacific is capable of two fundamentally different types of responses (OT and EP) with timescales and magnitude depending on the interplay of various factors, including how abruptly the system is perturbed and the rate of extra-tropical warming relative to the equatorial band. A related question is whether the inability of GCMs to capture the observed recent temperature and wind trends is indeed caused by an inaccurate representation of the transient IndoPacific OT response, which may be linked to persistent GCM biases affecting the cold tongue/warm pool complex, equatorial wind stress, the equatorial undercurrent and the ITCZ (e.g. Bellinger et al. 2013; Burls 
et al. 2017; Karnauskas et al., 2020; Li and Xie, 2014) as well as extra-tropical biases (Burls and Fedorov, 2014; Thomas and Fedorov, 2017; Kang et al., 2020). To investigate the impacts of GCM biases, Seager et al. (2019) use a simpler model based on thermodynamic atmosphere-ocean coupling linearized around the tropical mean state. The Pacific Ocean response to historical forcing within this model involves a strengthening of the zonal SST gradient and the Walker cell, which is more consistent with the observed changes than those seen in GCMs. Seager et al. (2019) argue that GCMs are unable to describe this strengthening due to biases in climatological relative humidity in the tropical Pacific and hence too weak evaporative response to wind changes and hence a weak WES feedback.

The goal of the present paper is to analyze the roles of the two types of tropical Pacific responses (OT and EP) in, respectively, the fast and slow evolution of the coupled ocean-atmosphere system within two different coupled models and investigate the causes of the model differences. By conducting a comparative analysis of these two GCMs with different Walker cell responses, we aim to gain further insights into why models are different in their estimates of projected changes to the Walker circulation, and which physical processes are key for setting the balance between the ocean thermostat and eastern Pacific warming responses.

The results presented here are complementary to, and expanding on the findings of Heede et al. (2020). While the previous work was aimed at reconciling several proposed mechanisms and combining them into a coherent framework, the present study applies this framework to explore the causes of model differences. The ultimate motivation for this comparison is to understand the key physical drivers behind the large inter-model spread in how the tropical Pacific responds to global warming - a critical issue affecting the robustness of future projections for the region.

The paper is structured as follows: section two describes the two GCMs used in the comparison and the experimental set-up. Section 3 contrasts the two models focusing on five areas: (3a) the development and characteristics of the fast OT-type response, $(3 \mathrm{~b})$ the link between the mean state ocean stratification and the strength of the OT, the roles of (3c) mean state winds and (3d) WES feedbacks in the OT response, and (3e) the role of the ocean tunnel effects in driving the slow eastern Pacific warming response. Section 4 discusses these findings and their implications for future warming patterns in the tropical Pacific.

\section{Model Set-up}

In this study, we use two different configurations of the Community Earth System Model (CESM). One set of simulations are carried out using the T31 gx3v7 configuration of CESM (v. 1.0.4. and therefore, essentially CCSM4 at the given resolution, see Gent et al. (2011) with a nominal $\sim 3.75^{\circ}$ atmospheric resolution and an oceanic latitudinal resolution of about $2^{\circ}$ increasing to $0.5^{\circ}$ near the equator. An identical set of simulations are then performed with a medium resolution version of CESM (1.9x2.5 gx1 v6 v. 1.2.1, or f19_g16) with a nominal $\sim 2^{\circ}$ atmospheric resolution and an oceanic latitudinal resolution of about $1^{\circ}$ increasing to $0.3^{\circ}$ near the equator. Hereafter, we refer to the coarse-resolution model as T31 
and to the medium resolution model as f19. Note that a part of the analysis using the T31-model also appeared in Heede et al. (2020). Here, we use those results as well as additional analysis to facilitate an inter-model comparison.

The two selected configurations of CESM have pronounced differences in their zonal Pacific response to radiative forcing in a range of warming scenarios. By choosing these two models, we can investigate what causes the stronger or weaker Walker cell responses, which will help understand the large spread of model estimated changes in the tropical Pacific.

We conduct a series of abrupt $\mathrm{CO}_{2}$ rise experiments with 2, 4, 8 and 16 times $\mathrm{CO}_{2}$ increase relative to the pre-industrial level. The abrupt $\mathrm{CO}_{2}$ experiments are useful for detecting changes directly resulting from greenhouse gas forcing as opposed to natural variability. As the rapid forcing increase might not accurately reflect realistic warming scenarios, we additionally conduct ramp experiments for each model where $\mathrm{CO}_{2}$ is increased linearly from pre-industrial level $(280 \mathrm{ppm})$ to $4 \mathrm{xCO}_{2}(1120 \mathrm{ppm})$ over 200 years and compare them to the abrupt $\mathrm{CO}_{2}$ rise experiments. In order to ensure that the experiments reach $4 \times \mathrm{CO}_{2}$ after 200 years, we use a linear $\mathrm{CO}_{2}$ ramp rather than the more conventional $1 \%$ forcing experiments. However, the forcing magnitudes of linear and $1 \% \mathrm{CO}_{2}$ increases are similar in the first 100 years of the simulation where the bulk of the fast response takes place, thus making the two approaches generally comparable.

The abrupt experiments are run for 400 years (200 years for the ramp experiment), and an ensemble approach is used to reduce the signature of natural variability, for instance associated with ENSO. Different ensemble members are generated following Kay et al. (2015) by adding random temperature anomalies with magnitude of $10^{-14} \mathrm{~K}$ to the same initial conditions. Five ensemble members are produced for T31 and 3 ensemble members for f19. All our experiments are initiated from the same start date and from two baseline simulations (called b.40), each corresponding to the given model resolution, made available by the National Center for Atmospheric Research (NCAR) with the 1850 radiative forcing that has been spun up for 507 years. Year zero in our simulations is the year at which $\mathrm{CO}_{2}$ is added to the atmosphere (instantaneously or ramped) in all experiments, except the control, which continues the baseline experiments but with added ensemble members.

As part of our analysis, we will use several temperature gradient metrics. To best capture the magnitude of the fast ocean thermostat type response (including its westward Walker cell shift), we define the IndoPacific SST gradient as the SST difference between the Indo-Pacific warm pool $\left(80^{\circ} \mathrm{E}\right.$ to $\left.130^{\circ} \mathrm{E}\right)$ and the central-eastern Pacific ( $180^{\circ} \mathrm{E}$ to $\left.280^{\circ} \mathrm{E}\right)$. To best capture long term changes in ocean dynamics associated with the oceanic tunnel in the Pacific Ocean, we use two additional metrics: the zonal Pacific gradient defined as the upper ocean $(50 \mathrm{~m})$ temperature difference between the West Pacific $\left(5^{\circ} \mathrm{S}\right.$ to $5^{\circ} \mathrm{N}$; $20^{\circ} \mathrm{E}$ to $150^{\circ} \mathrm{E}$ ) minus that in the East Pacific cold tongue region ( $5^{\circ} \mathrm{S}$ to $5^{\circ} \mathrm{N} ; 205^{\circ} \mathrm{E}$ to $280^{\circ} \mathrm{E}$ ). The meridional gradient is defined as the difference between the mean upper-ocean $(50 \mathrm{~m})$ temperature of the tropical Pacific $\left(5^{\circ} \mathrm{S}\right.$ to $\left.5^{\circ} \mathrm{N}\right)$ and an average of the northern and southern Pacific. The southern Pacific is 
defined as $50^{\circ} \mathrm{S}$ to $20^{\circ} \mathrm{S}$ and $200^{\circ}$ to $280^{\circ} \mathrm{E}$. The northern Pacific is defined as $20^{\circ}$ to $50^{\circ} \mathrm{N}$ and $160^{\circ}$ to $240^{\circ} \mathrm{E}$. These regions are considered the main source regions for equatorial upwelling (e.g. Thomas and Fedorov,2017).

\section{Results}

\section{a. The strength and zonal and meridional structure of the Indo-Pacific ocean thermostat}

Responding to the abruptly increased $\mathrm{CO}_{2}$ concentration in the atmosphere, both models show a characteristic fast evolution that includes an initial strengthening of the zonal east-west SST gradient and zonal winds integrated across the Pacific (relative to the control simulation), followed by a weakening of this SST gradient and zonal winds when the system moves toward equilibrium (Fig. 1). However, the timescales and magnitude of changes varies substantially between the two models. As expected, the magnitude of changes also varies across different $\mathrm{CO}_{2}$ forcings, yielding the most subdued signal in the $2 \mathrm{xCO}_{2}$ experiments.

The initial fast response seen in the two models, characterized by stronger gradients and a generally stronger Pacific Walker cell relative to the control simulation, has been described previously by Heede et al. (2020) as a transient Indo-Pacific thermostat (also see Zhang et al. 2019), with a characteristic westward shift of the Walker cell, driven both by wind-evaporation feedbacks and ocean dynamics.

The T31 model shows a relatively weak initial strengthening of the zonal SST gradient and integrated wind stress lasting 20-30 years, as compared to the 19 model whose initial response is stronger and lasts about 50 years (Fig. 1). As evident from Fig. 2, the initial equatorial response is accompanied by strong "cooling" anomalies (relative to the mean tropical warming) in the trade wind belts, especially pronounced in the f19 model (Fig. 2), which coincide with the strengthening of the northeasterly and southeasterly winds. Along the equator, the initial response is characterized by the strengthening and westward displacement of wind stress, indicative of a stronger and westward shifted Walker circulation over the Pacific (Fig. 3). These Walker cell changes are driven in part by enhanced warming over the Indian Ocean and the Maritime continent, inducing a Gill-type response (Matsuno 1966, Gill 1980 and recently Hu and Fedorov 2019) with stronger winds over the central and western Pacific. Thus, the initial system response resembles an ocean thermostat mechanism, albeit with a zonal and meridional structure different from that originally proposed by Clement et al. (1996). The thermostat effect, including the strengthening of the east-west equatorial SST gradient and the Walker cell amplified by the Bjerknes feedback, turns out to be significantly stronger in the higher-resolution model (f19), the reasons for which we will analyze in subsequent sections.

Our ramp experiments show a generally similar fast response, even though for the gradual $\mathrm{CO}_{2}$ increase the thermostat response is slower to emerge and lasts for about 70-100 years (Fig. 4). After 100 years, the SST gradient becomes weaker than that in the control experiment, and the induced changes to the SST gradient gradually converge to the slow, quasi-equilibrium response of the abrupt experiments. While the 
transient ocean-thermostat type response appears slightly stronger and longer lasting in the f19 model, compared to the T31 model, the differences between the two models are somewhat smaller in the ramp experiments, compared to the abrupt experiments.

\section{b. The ocean thermocline structure and the Bjerknes feedback}

The effect of the westward shift of the Walker cell on the ocean thermal structure along the equator is a cold subsurface anomaly in the central and eastern equatorial Pacific, which reflects the local shoaling of the thermocline, illustrated in the schematic in Fig. 5. In turn, this cold anomaly causes a colder central equatorial Pacific SST, which strengthens the Walker cell via the Bjerknes feedback.

The difference in the strength and position of the initial response between the two models can in part be traced to the structure of mean winds and upper ocean stratification simulated by the models along the equator. The T31 model has weaker mean easterly winds with a broader zonal profile (Fig. 3a). The corresponding upper-ocean thermal structure shows a less stratified thermocline (Fig. 6a). The f19 model, in contrast, has a sharper wind stress profile, stronger winds (Fig. 3b) and a more stratified thermocline (Fig. 6b). Thus, due to the stronger stratification in the f19 model, any displacement of the thermocline will lead to larger upper-ocean temperature anomalies, which in turn will create a stronger ocean thermostat effect in response to an initial perturbation in wind stress from atmospheric forcing. This is illustrated in Fig. $6 \mathrm{c}$ and $6 \mathrm{~d}$, where the upper ocean cold anomaly is generally consistent with the shape and strength of the mean state thermocline profile.

Thus, the higher sensitivity of SST to thermocline displacement can account for a stronger Bjerknes feedback in F19. To illustrate this, we consider the joint temporal evolution of the changes in SST and wind stress in a Hovmöller diagram. Fig 7 shows, as expected, a strong correlation between the wind stress and SST changes. Importantly, the f19 model shows much stronger variation in central Pacific wind stress than the T31, which in turn can be related to the shaper thermocline in figure 6. Consequently, a stronger Bjerknes feedback in the f19-model facilitates a stronger OT-type response to forcing due to the stronger upper ocean temperature anomalies associated with initial wind changes.

\section{c. The mean winds and the WES feedback}

In addition to the upper-ocean stratification, the mean state winds also affect the fast response by controlling latent heat fluxes. In a model with stronger mean state surface winds, a radiative forcing can be offset by increased latent heat fluxes more efficiently than in a model with weaker mean state surface winds. To investigate the extent to which model differences in the mean wind field influence the differences in the latent heat flux responses in the two GCMs, we analyze the linearized latent heat flux response to a uniform $1 \mathrm{~K}$ forcing using the conventional bulk formula for evaporative fluxes, $E$ :

$$
E=L C_{L} \rho_{\text {air }} W(1-\mathcal{H}) q_{s}
$$


Where $L$ is the latent heat of evaporation, $p_{\text {air }}$ is an average density of air near the surface, $W$ is windspeed $\mathrm{H}$ is relative humidity, $\mathrm{C}_{\mathrm{L}}$ is the bulk transfer coefficient for water vapor (here we use $\mathrm{CL}=10^{-3}$ ) and $\mathrm{q}_{\mathrm{s}}$ is saturation specific humidity. We can further approximate $q_{s} \approx \frac{0.622}{P_{\text {air }}} e_{s}$. where $\mathrm{e}_{\mathrm{s}}$ is the saturation vapor pressure and $\mathrm{p}_{\text {air }}$ is the average atmospheric pressure at the surface. Considering a linearized response to temperature changes around the mean state, we can express changes in $E$ as $\Delta E$ given by:

$$
\Delta E=L C_{L} \rho_{\text {air }} W_{0}\left(1-\mathcal{H}_{0}\right)\left(\frac{0.622}{P_{\text {air }}}\right) \frac{d e_{s}}{d T} \Delta T=L C_{L} \rho_{\text {air }} W_{0}\left(1-\mathcal{H}_{0}\right)\left(\frac{0.622}{P_{\text {air }}}\right) \frac{L e_{s 0}}{R^{v} T_{0}{ }^{2}} \Delta T
$$

Where $\mathrm{W}_{0}, \mathrm{H}_{0}, \mathrm{e}_{\mathrm{s} 0}$, and $\mathrm{T}_{0}$ denote mean state fields - windspeed, relative humidity, saturation vapor pressure and temperature, respectively, and $\mathrm{R}^{\mathrm{V}}$ is the ideal gas constant for water vapor.

Figure 8 shows the linearized latent heat response based on mean state fields and $D T=1 \mathrm{~K}$ alongside the fast and slow responses from the fully coupled models. Along the equator, the linearized response is consistent with the fully-coupled fast response, and the f19-model showing a much stronger latent heat response compared to the T31 model. This increase in latent heat loss suppresses surface warming over the central Pacific, reinforcing the Indo-Pacific SST gradient that drives the ocean thermostat-type response.

While the fast response's main feature is lack of warming across the equatorial Pacific and in the trade wind belts, the slow response, starting to emerge after 20-50 years, is characterized by enhanced equatorial Pacific warming evident in both models (Fig 2). For the T31 model, this warming anomaly appears strictly in the eastern part of the basin, while the f19 model exhibits a narrower tropical warming extending to the central Pacific with a less pronounced east-west gradient (Fig. 2). We can account for these differences and, more generally, for the transition from the fast to slow response by considering the off-equatorial evaporative cooling patterns and the effects of the oceanic bridge, discussed in the next sections.

\section{d. The role of wind-evaporation feedback}

Increased wind strength in the trade winds belts is associated with greater latent heat fluxes, which act to cool the surface of the ocean. The ability of the ocean surface to balance the $\mathrm{CO}_{2}$-induced increase in the downward radiation flux with upward latent heat fluxes is most effective in areas that have strong mean state winds and relatively warm SSTs, i.e. in the trade wind belts just off the equator (i.e Seager and Murtugudde, 1997). This enhanced cooling by evaporation may in turn affect the SST gradient towards other areas of the ocean, for example towards and along the equator, where weaker winds and/or colder temperatures means that evaporative cooling is less effective. This meridional SST gradient can thus 
strengthen the winds off-equator, following the wind-evaporation-SST (WES) feedback (e.g. Xie and Philander, 1994 and Fig. 9).

After 200 years, as the system has moved towards equilibrium, the two models still exhibit stronger southeasterly and northeasterly winds in the eastern and central Pacific between 5-10 $\mathrm{N} / \mathrm{S}$, and enhanced latent heat loss on both sides of equator (Figs. $8 \mathrm{~g}$ and $8 \mathrm{~h}$ ) accompanied by reduced warming. This enhanced latent heat loss off the equator is well reproduced by the linearized approach (Fig. 8c,d). These results confirm that the WES feedback is a robust feature of the Pacific warming pattern, and is stronger in the $\mathrm{f} 19$ model. Following the same argument as in section $\mathrm{c}$, the model difference can in part be explained by comparing the mean state surface winds and latent heat fluxes between the two models (Fig. 8a and 8b): The f19 model's cold tongue is narrower in meridional extent, and mean latent heat fluxes and winds are stronger just off-equator, especially in the northern hemisphere, compared to the T31 model. While the slow response somewhat differs from the linearized prediction based on mean state fields, which is expected, given that surface winds may change significantly after 200 years, the strength of the off-equatorial latent heat response in the eastern Pacific in the models can still be traced to their mean winds: stronger mean winds in the f19-model generate a stronger latent heat response, which in turn sets up a stronger SST gradient in the direction of the southeasterly and northeasterly winds. This has implications for the evolution of meridional ocean circulation, which affects the strength of eastern Pacific warming as discussed in the following section.

\section{e. The transition from the fast to slow response and the role of the ocean tunnel}

The gradual warming of the tropical Pacific upper ocean leads to a dissipation of central Pacific cooling anomalies, which weakens the effectiveness of the ocean thermostat, and associated strengthening of the of Walker cell reduces after 25-50 years (Figs 1a, 1b). From an ocean dynamics perspective, the magnitude and timescale of this transition are determined by two processes: the weakening of the subtropical cells (STCs) that reduces the supply of cold water to the equatorial region and enhanced warming of extra-tropical waters relative to the tropics that ultimately increases the temperature of the upwelled water.

The T31 model exhibits an overall weakening of the of STCs in both hemispheres (see Fig. 10 for $2 \mathrm{xCO}_{2}$ and $4 \mathrm{xCO}_{2}$ ). The $\mathrm{f} 19$ model, however, shows more complicated changes with a narrowing of the STCs in both hemispheres, a weakening at the equator but a strengthening off-equator. This strengthening can, again, be related to the strengthening of winds on both sides of the equator described in section $d$.

Given nonuniform changes in STCs, to demonstrate the effect of STC slowdown in the equatorial band, we calculate changes in vertical velocity averaged below the mixed layer down to a 500m depth, between $5^{\circ} \mathrm{S}$ and $5^{\circ} \mathrm{N}$, and from the western $\left(150^{\circ} \mathrm{E}\right)$ to the eastern $\left(280^{\circ} \mathrm{E}\right)$ Pacific. By considering this broad average, we can track the slowdown of the large-scale STCs, which transport colder water from extratropical source regions, as opposed to the smaller tropical cells that primarily re-circulate water within the equatorial band (i.e. Brown et al.,2007). We see that in both models there is a slowdown of net vertical 
transport associated with STCs during the first decades of the experiments (Fig. 11), which lasts throughout the 400-year simulation. The computed differences between the models are consistent with Fig. 10, showing that the STC slowdown is more drastic in the T31 model, as the changes in the f19 model are partially compensated by the strengthening of trade winds as part of the WES feedback.

To trace the effect of extra-tropical warming on the equatorial dynamics, we calculate changes in stratification between the mixed layer $(0-50 \mathrm{~m})$ and the upper ocean below the mixed layer, defined as 50$500 \mathrm{~m}$, which covers the vertical extent of the subtropical cells in the equatorial band (Fig. 10). Fig. 12 shows the changes in stratification with time. Initially, the equatorial stratification increases as the mixed layer warms faster than the deeper layers of the ocean. After 200 years, this increase is greatly reduced as the STCs brings warmer water from the extra-tropics to equator, and after 350 years, the ocean stratification finally weakens relative to the control state as the extra-tropics warm more than the tropical regions. The stratification changes are greater in the high $\mathrm{CO}_{2}$ scenarios and small in the $2 \mathrm{xCO}_{2}$ experiment. Furthermore, the subsurface ocean warms faster and to a larger degree in the T31 model as compared to the f19 model.

The warming of extra-tropical waters relatively to the equatorial band can be also measured by changes in the meridional upper-ocean temperature gradient (Fig. 13). We observe that in both models this temperature gradient generally reduces during the slow response, except in the $2 \mathrm{xCO}_{2}$ experiment, meaning that the extra-tropical oceans are gradually warming more than the equator in these experiments. This factor, due to the effect of the oceanic tunnel, should lead to a reduced zonal-upper ocean gradient (Burls and Fedorov 2014, Fedorov et al. 2015). From Fig. 13 we indeed see that a linear positive relationship between the zonal and meridional temperature gradients develop after about 50-100 years. However, despite the fact that both models have a reduction in the meridional temperature gradient with $\mathrm{CO}_{2}$ forcing, the slope of the linear relationship between the meridional and zonal temperature gradients is much steeper for the T31 model than for the f19 model (Fig. 13). The different rates of STC slowdown between the models can account for this difference in slope.

\section{Discussion}

The results of our analysis comparing the responses of two models to abrupt $\mathrm{CO}_{2}$ forcing show that in both cases, the coupled ocean-atmosphere system undergoes a fast transient adjustment in the first decades of the simulation, followed by a slow adjustment that eventually allows the system to reach equilibrium. The fast response is ocean thermostat-like (OT), while the slow response leads to the establishment of the eastern equatorial Pacific (EP) pattern with a weaker Walker circulation. However, the T31 model displays only a weak ocean thermostat but a strong EP warming. In contrast, the f19 model shows a strong OT but a very weak eventual reduction in the zonal SST gradient and the Walker cell - those changes are particularly small in the $2 \mathrm{xCO}_{2}$ experiment. The OT-type response is clearly evident in the abrupt $\mathrm{CO}_{2}$-forcing experiments, but it also appears as a robust feature of the experiments 
with a ramp $\mathrm{CO}_{2}$ increase. In the gradual forcing experiments the OT response, while slower to emerge, can persist longer, up to 100 years.

During the fast response, differences in evaporative cooling within the trade wind belts appear to play a key role in the spatial patterns and temporal evolution of changes to the Walker circulation and the zonal SST gradient. The f19 models exhibits a strong increase in wind and latent heat fluxes in the trade wind belts and the central equatorial Pacific, which is linked to stronger climatological winds and wind convergence in the central and western Pacific, driving a strong ocean thermostat type response along the equatorial Pacific. The climatological winds are weaker in the T31, and so is the ocean thermostat response. Even though the OT response is eventually replaced by the EP warming on the equator, a strong signature of enhanced evaporative cooling over the regions of southeasterly and northeasterly trade winds persist off the equator, in particular in the f19 model.

Another key difference between the two models that sets the strength of the ocean thermostat is related to the profile of upper-ocean stratification. As initial wind changes force the thermocline to shift westward and shoal in the central and eastern equatorial Pacific, the resultant effect on the equatorial SST depends on the magnitude of upper-ocean temperature anomalies associated with this thermocline displacement, which in turn depends on ocean background stratification. A stronger stratification means a higher SST sensitivity to thermocline displacement. As such, a more strongly stratified thermocline in the f19 model explains a higher SST sensitivity to thermocline displacement, a stronger Bjerknes feedback in response to wind changes, and hence a stronger ocean thermostat response.

The timescales at which the stronger equatorial winds and OT response subside, giving way to the EP warming, appear to depend critically on the magnitude of the net slowdown of the STCs and the warming of waters subducted in the extra-tropics and then upwelled at the equator. The arrival of this warm water gradually reduces the initial increase in vertical stratification along the equator that occurs in the first decades after the forcing was imposed.

On longer timescales, as the system approaches the equilibrium, the enhanced warming of the extratropics relative to the equatorial belt, and the corresponding reduction of the meridional temperature gradient between the equator and the extra-tropics, may further contribute to the strength of the EP pattern, especially in T31 model. These results highlight the fundamental relationship between equatorial and off-equatorial ocean dynamics, as suggested by previous studies (McCreary and Lu 1994; Gu and Philander, 1997; Seager and Murtugudde, 1997; Huang and Liu 1997; and more recently Burls and Fedorov, 2014 and Fedorov et al., 2015) arguing that the mean east-west tropical temperature gradient should be tightly related to the tropical extra-tropical gradient (e.g. Fedorov et al. 2015). However, our results show that relationship between extra-tropical warming and tropical zonal SST gradients is not universal across the models because changes in the strength and structure of STCs also may play an important role, setting a different slope of the relationship between the zonal and meridional gradient. 
A related important point is that changes in oceanic and atmospheric circulation patterns cannot be simply classified as weakening or strengthening, but they may also change spatially. For example, in both models the Walker circulation exhibits a characteristic westward shift, and the STCs can exhibit an equatorward narrowing, in particular in the $\mathrm{f} 19$ model, which may in turn change the make-up of the source waters upwelled at equator (Zeller et al., 2020). Thus, both the magnitude of changes and changes in the spatial structure should be considered when analyzing the tropical-extra-tropical connection with regard to the tropical Pacific response to warming.

In the context of mechanisms responsible for weakening of the Walker cell, it is also important to keep in mind that the effects of local atmospheric processes such as evaporative damping, cloud feedbacks and thermodynamic constraints on atmospheric circulation (e.g. Erfani \& Burls, 2019; Merlis \& Schneider, 2011; Vecchi \& Soden, 2007) can be superimposed on the ocean thermostat and oceanic tunnel mechanisms discussed here. For example, Heede et al. (2020) investigated the slowdown of the ascending branch of the Walker cell in the T31 model and found that pressure velocity (omega) in the mid-troposphere decreased over the Pacific warm pool at a rate of $5-6 \%$ per ${ }^{\circ} \mathrm{C}$ of warming, yet it increased over the Maritime continent, contributing to a westward shift rather than a slowdown of the Walker cell. A further comparison between slab-ocean and fully coupled simulations revealed a much more pronounced reduction in the zonal SST gradient in the fully coupled simulations, confirming the important role of the dynamical ocean and ocean-atmosphere interactions in setting the magnitude of the Walker cell weakening as part of the system's slow response.

It is noteworthy that while we are comparing two models within the same CESM family, several major characteristics of how these models respond to radiative forcing are also found among a much broader model selection in the CMIP archives. Specifically, an analysis of abrupt $4 \mathrm{xCO}_{2}$ experiments in CMIP6 shows that a large majority of the models exhibit similar fast and slow responses in the zonal SST gradient, albeit with a large spread (Heede and Fedorov,_2021,_[in review, pre-print available]). Likewise, for the CMIP5 data, DiNezio et al. (2012). documented a time mean change in the upper-ocean temperature profile after $\mathrm{CO}_{2}$ doubling, which resembles the patterns observed in these two models. This suggests that the strengthening of zonal winds in the central or western equatorial Pacific, leading to the westward shift of the thermocline structure, is a common response in the models.

Furthermore, the lack of, or suppressed warming over the Pacific trade wind belts is a feature observed in other models as well, albeit to varying degrees. While virtually all models show a clear lack of warming in the subtropics of the southern hemisphere stretching from the coast of South America towards the equator, the models are much more uncertain in the Pacific trends in the northern hemisphere (Ceppi et al., 2018, Ying et al., 2016 Zheng et al., 2016). This indicates that another potential source of uncertainty and large model spread of the projections for the mean zonal SST gradients in the Pacific is relates to the strength and position of winds in the northern hemisphere, and the associated response of latent heat fluxes in the subtropics. 
Overall, the different responses between the two models in this study can be linked to their different mean states: T31 has a weaker stratified upper ocean and weaker winds compared to the f19 model, which appears to reduce the strength of the OT type response but increase the strength of the subsequent EP warming. This is an important point in the context of understanding why CMIP models are unable to capture recent decadal trends in the region, given that the mean CMIP model wind stress along the equator is underestimated at peak strength in the central Pacific but overestimated in the western Pacific compared to the observations (Lee et al., 2013; Bellenger et al., 2014) thus possibly more prone to a diffuse ocean thermostat response, analogous to the T31 model. This potential key link between the wind stress/cold tongue biases and the inability of models to capture the recent trends should be a point for further investigation. Likewise, which model parameters are responsible for mean state differences, such as the model resolution, subgrid parameterizations, or the representation of clouds and convection, is an important question for future studies.

Our additional ramp experiments, where $\mathrm{CO}_{2}$ rises linearly at a rate in the range of projected future scenarios, show the same type of the transient ocean-thermostat and the subsequent EP warming/weaker Walker regimes as the abrupt experiments, though the OT response is more muted but longer lasting in the ramp experiments. This similarity between the abrupt and gradual $\mathrm{CO}_{2}$ experiments brings further confidence to the possibility that the transient ocean thermostat type response may be playing an important role in shaping the ongoing changes in the tropical Pacific.

In summary, this paper illustrates the key differences between the fast and slow tropical Pacific responses to $\mathrm{CO}_{2}$ forcing and how these differences are related to the relative strength of the ocean thermostat mechanism versus the ocean tunnel and other mechanisms that cause the eastern equatorial Pacific warming. The ocean thermostat mechanism is understood as involving the entire tropical Indian ocean in addition to the Pacific as well as the regions of the Pacific southeasterly and northeasterly trade wind belts. The oceanic tunnel mechanism includes both the weakening of the subtropical cells (STCs) and the warming of water subducted and transported by these cells to the equator. The balance of these mechanisms is intimately linked to the subtropical warming patterns and atmospheric and oceanic circulation changes, which vary between the models. Whether the failure of GCMs to capture the recently observed trend of stronger easterly winds in the Pacific is connected to an inaccurate representation of the $\mathrm{CO}_{2}$-induced ocean thermostat-type response will be investigated in the future studies.

\section{Declarations}

\section{Acknowledgements}

U.K.H is supported by NASA FINESST Fellowship (80NSSC20K1634). A.V.F. is supported by grants from the NSF (AGS-0163807) and NASA (NNX17AH21G), the ARCHANGE project of the "Make our planet great again" program (CNRS, France), and the Guggenheim fellowship. N.J.B. is supported by NSF AGS1613318, AGS-1844380 and the Alfred P. Sloan Foundation as a Research Fellow. We would like to 
acknowledge high-performance computing support from Cheyenne (https://doi.org/10.5065/D6RX99HX) provided by NCAR's Computational and Information Systems Laboratory, sponsored by the NSF.

Funding: U.K.H is supported by NASA FINESST Fellowship (80NSSC20K1634). A.V.F. is supported by grants from the NSF (AGS-0163807) and NASA (NNX17AH21G), the ARCHANGE project of the "Make our planet great again" program (CNRS, France), and the Guggenheim fellowship. N.J.B. is supported by NSF AGS-1613318, AGS-1844380 and the Alfred P. Sloan Foundation as a Research Fellow.

Conflicts of interest/Competing interests: The authors declare no competing interests

Availability of data and material: The datasets generated during and/or analysed during the current study are available from the corresponding author on reasonable request.

Code availability: The code files used to generate figures for this study are available from the corresponding author on reasonable request.

Ethics approval: N/A

Consent for publication to participate: N/A

\section{References}

Ashok, K. and Yamagata, T. (2009) 'The El Niño with a difference', Nature, 461(7263), pp. 481-484.

Bellenger, H. et al. (2014) 'ENSO representation in climate models: from CMIP3 to CMIP5', Climate Dynamics, 42(7), pp. 1999-2018. doi: 10.1007/s00382-013-1783-z.

Bjerknes, J. (1969) 'Atmospheric teleconnections from the equatorial Pacific', Monthly weather review, 97(3), pp. 163-172.

Brown, J. N., Godfrey, J. S. and Schiller, A. (2007) 'A Discussion of Flow Pathways in the Central and Eastern Equatorial Pacific', Journal of Physical Oceanography, 37(5), pp. 1321-1339. doi:

10.1175/JP03042.1.

Burls, N. J. and Fedorov, A. V. (2014) 'What controls the mean east-west sea surface temperature gradient in the equatorial Pacific: The role of cloud albedo', Journal of Climate, 27(7), pp. 2757-2778.

Cai, W. et al. (2015) 'ENSO and greenhouse warming', Nature Climate Change, 5(9), pp. 849-859.

Cane, M. A. et al. (1997) 'Twentieth-Century Sea Surface Temperature Trends', Science, 275(5302), pp. 957-960. doi: 10.1126/science.275.5302.957.

Clement, A. C. et al. (1996) 'An ocean dynamical thermostat', Journal of Climate, 9(9), pp. 2190-2196. 
Coats, S. and Karnauskas, K. B. (2017) 'Are simulated and observed twentieth century tropical Pacific sea surface temperature trends significant relative to internal variability?', Geophysical Research Letters, 44(19), pp. 9928-9937.

Collins, M. et al. (2010) 'The impact of global warming on the tropical Pacific Ocean and El Niño', Nature Geoscience, 3(6), pp. 391-397.

Dijkstra, H. A. and Neelin, J. D. (1995) 'Ocean-atmosphere interaction and the tropical climatology. Part II: Why the Pacific cold tongue is in the east', Journal of Climate, 8(5), pp. 1343-1359.

DiNezio, P. N. et al. (2009) 'Climate response of the equatorial Pacific to global warming', Journal of Climate, 22(18), pp. 4873-4892.

DiNezio, P. N. et al. (2012) 'Mean climate controls on the simulated response of ENSO to increasing greenhouse gases', Journal of climate, 25(21), pp. 7399-7420.

England, M. H. et al. (2014) 'Recent intensification of wind-driven circulation in the Pacific and the ongoing warming hiatus', Nature climate change, 4(3), pp. 222-227.

Erfani, E. and Burls, N. J. (2019) 'The Strength of Low-Cloud Feedbacks and Tropical Climate: A CESM Sensitivity Study', Journal of Climate, 32(9), pp. 2497-2516.

Fedorov, A. V. et al. (2015) 'Tightly linked zonal and meridional sea surface temperature gradients over the past five million years', Nature Geoscience, 8(12), pp. 975-980.

Fedorov, A. V. and Philander, S. G. (2000) 'Is El Niño changing?', Science, 288(5473), pp. 1997-2002.

Gent, P. R. et al. (2011) 'The community climate system model version 4', Journal of climate, 24(19), pp. 4973-4991.

Griffiths, G. M. et al. (2005) 'Change in mean temperature as a predictor of extreme temperature change in the Asia-Pacific region', International Journal of Climatology: A Journal of the Royal Meteorological Society, 25(10), pp. 1301-1330.

Gu, D. and Philander, S. G. (1997) 'Interdecadal climate fluctuations that depend on exchanges between the tropics and extratropics', Science, 275(5301), pp. 805-807.

Heede, U. and Fedorov, A. (2021) 'Eastern equatorial Pacific warming delayed by aerosols and thermostat response to CO2'. Preprint available: https://assets.researchsquare.com/files/rs-133479/v1/386c7df2e054-425b-a1a9-906448b9b7f1.pdf

Heede, U. K., Fedorov, A. V. and Burls, N. J. (2020) 'Timescales and mechanisms for the Tropical Pacific response to global warming: a tug of war between the Ocean Thermostat and weaker Walker', Journal of Climate. doi: 10.1175/JCLI-D-19-0690.1. 
Held, I. M. and Soden, B. J. (2006) 'Robust responses of the hydrological cycle to global warming', Journal of climate, 19(21), pp. 5686-5699.

Hu, S. and Fedorov, A. V. (2017) 'The extreme El Niño of 2015-2016 and the end of global warming hiatus', Geophysical Research Letters, 44(8), pp. 3816-3824. doi:

https://doi.org/10.1002/2017GL072908.

$\mathrm{Hu}, \mathrm{S}$. and Fedorov, A. V. (2019) 'Indian Ocean warming can strengthen the Atlantic meridional overturning circulation', Nature Climate Change, 9(10), pp. 747-751. doi: 10.1038/s41558-019-0566-x.

Jin, F.-F. (1996) 'Tropical ocean-atmosphere interaction, the Pacific cold tongue, and the El Niño-Southern Oscillation', Science, 274(5284), pp. 76-78.

Kang, S. M. et al. (2020) 'Walker circulation response to extratropical radiative forcing', Science Advances, 6(47), p. eabd3021. doi: 10.1126/sciadv.abd3021.

Karnauskas, K. B. et al. (2020) 'The Pacific Equatorial Undercurrent in Three Generations of Global Climate Models and Glider Observations', Journal of Geophysical Research: Oceans, 125(11), p. e2020JC016609. doi: https://doi.org/10.1029/2020JC016609.

Kay, J. E. et al. (2015) 'The Community Earth System Model (CESM) large ensemble project: A community resource for studying climate change in the presence of internal climate variability', Bulletin of the American Meteorological Society, 96(8), pp. 1333-1349.

Knutson, T. R. and Manabe, S. (1995) 'Time-mean response over the tropical Pacific to increased C02 in a coupled ocean-atmosphere model', Journal of Climate, 8(9), pp. 2181-2199.

Kociuba, G. and Power, S. B. (2015) 'Inability of CMIP5 models to simulate recent strengthening of the Walker circulation: Implications for projections', Journal of Climate, 28(1), pp. 20-35.

Kosaka, Y. and Xie, S.-P. (2013) 'Recent global-warming hiatus tied to equatorial Pacific surface cooling', Nature, 501(7467), pp. 403-407.

Lee, S.-K. et al. (2015) 'Pacific origin of the abrupt increase in Indian Ocean heat content during the warming hiatus', Nature Geoscience, 8(6), p. 445.

Lee, T. et al. (2013) 'Evaluation of CMIP3 and CMIP5 Wind Stress Climatology Using Satellite Measurements and Atmospheric Reanalysis Products', Journal of Climate, 26(16), pp. 5810-5826. doi: 10.1175/JCLI-D-12-00591.1.

Li, G. and Xie, S.-P. (2014) 'Tropical biases in CMIP5 multimodel ensemble: The excessive equatorial Pacific cold tongue and double ITCZ problems', Journal of Climate, 27(4), pp. 1765-1780. 
Luo, J.-J., Sasaki, W. and Masumoto, Y. (2012) 'Indian Ocean warming modulates Pacific climate change', Proceedings of the National Academy of Sciences, 109(46), pp. 18701-18706.

Luo, Y. et al. (2017) 'The Role of Ocean Dynamical Thermostat in Delaying the El Niño-Like Response over the Equatorial Pacific to Climate Warming', Journal of Climate, 30(8), pp. 2811-2827. doi: 10.1175/JCLI-D-16-0454.1.

Ma, S. and Zhou, T. (2016) 'Robust strengthening and westward shift of the tropical Pacific Walker circulation during 1979-2012: A comparison of 7 sets of reanalysis data and 26 CMIP5 models', Journal of Climate, 29(9), pp. 3097-3118.

McCreary Jr, J. P. and Lu, P. (1994) 'Interaction between the subtropical and equatorial ocean circulations: The subtropical cell', Journal of Physical Oceanography, 24(2), pp. 466-497.

McPhaden, M. J., Santoso, A. and Cai, W. (2020) El Niño Southern Oscillation in a Changing Climate. John Wiley \& Sons.

Meng, Q. et al. (2012) 'Twentieth century Walker circulation change: Data analysis and model experiments', Climate dynamics, 38(9-10), pp. 1757-1773.

Merlis, T. M. and Schneider, T. (2011) 'Changes in zonal surface temperature gradients and Walker circulations in a wide range of climates', Journal of climate, 24(17), pp. 4757-4768.

Pierrehumbert, R. T. (2000) 'Climate change and the tropical Pacific: The sleeping dragon wakes', Proceedings of the National Academy of Sciences, 97(4), pp. 1355-1358.

Plesca, E., Grützun, V. and Buehler, S. A. (2018) 'How robust is the weakening of the Pacific Walker circulation in CMIP5 idealized transient climate simulations?', Journal of Climate, 31(1), pp. 81-97.

Seager, R. et al. (2019) 'Strengthening tropical Pacific zonal sea surface temperature gradient consistent with rising greenhouse gases', Nature Climate Change, 9(7), pp. 517-522.

Seager, R. and Murtugudde, R. (1997) 'Ocean dynamics, thermocline adjustment, and regulation of tropical SST', Journal of climate, 10(3), pp. 521-534.

Stuecker, M. F. et al. (2020) 'Strong remote control of future equatorial warming by off-equatorial forcing', Nature Climate Change, pp. 1-6.

Thomas, M. D. and Fedorov, A. V. (2017) 'The eastern subtropical Pacific origin of the equatorial cold bias in climate models: A Lagrangian perspective', Journal of Climate, 30(15), pp. 5885-5900.

Tokinaga, H. et al. (2012) 'Regional patterns of tropical Indo-Pacific climate change: Evidence of the Walker circulation weakening', Journal of Climate, 25(5), pp. 1689-1710. 
Vecchi, G. A. et al. (2006) 'Weakening of tropical Pacific atmospheric circulation due to anthropogenic forcing', Nature, 441(7089), pp. 73-76.

Vecchi, G. A. and Soden, B. J. (2007) 'Global warming and the weakening of the tropical circulation', Journal of Climate, 20(17), pp. 4316-4340.

Xie, S.-P. et al. (2010) 'Global warming pattern formation: Sea surface temperature and rainfall', Journal of Climate, 23(4), pp. 966-986.

Xie, S.-P. and Philander, S. G. H. (1994) 'A coupled ocean-atmosphere model of relevance to the ITCZ in the eastern Pacific', Tellus A, 46(4), pp. 340-350.

Ying, J., Huang, P. and Huang, R. (2016) 'Evaluating the formation mechanisms of the equatorial Pacific SST warming pattern in CMIP5 models', Advances in Atmospheric Sciences, 33(4), pp. 433-441. doi: $10.1007 / \mathrm{s} 00376-015-5184-6$.

Zeller, M. et al. (2020) 'Subtropical-tropical pathways of spiciness anomalies and their impact on equatorial Pacific temperature', Climate Dynamics. doi: 10.1007/s00382-020-05524-8.

Zhang, L. et al. (2019) 'Indian Ocean Warming Trend Reduces Pacific Warming Response to Anthropogenic Greenhouse Gases: An Interbasin Thermostat Mechanism', Geophysical Research Letters, 46(19), pp. 10882-10890.

\section{Figures}


a) Indo West Pacific - East Pacific $\Delta$ SST T31
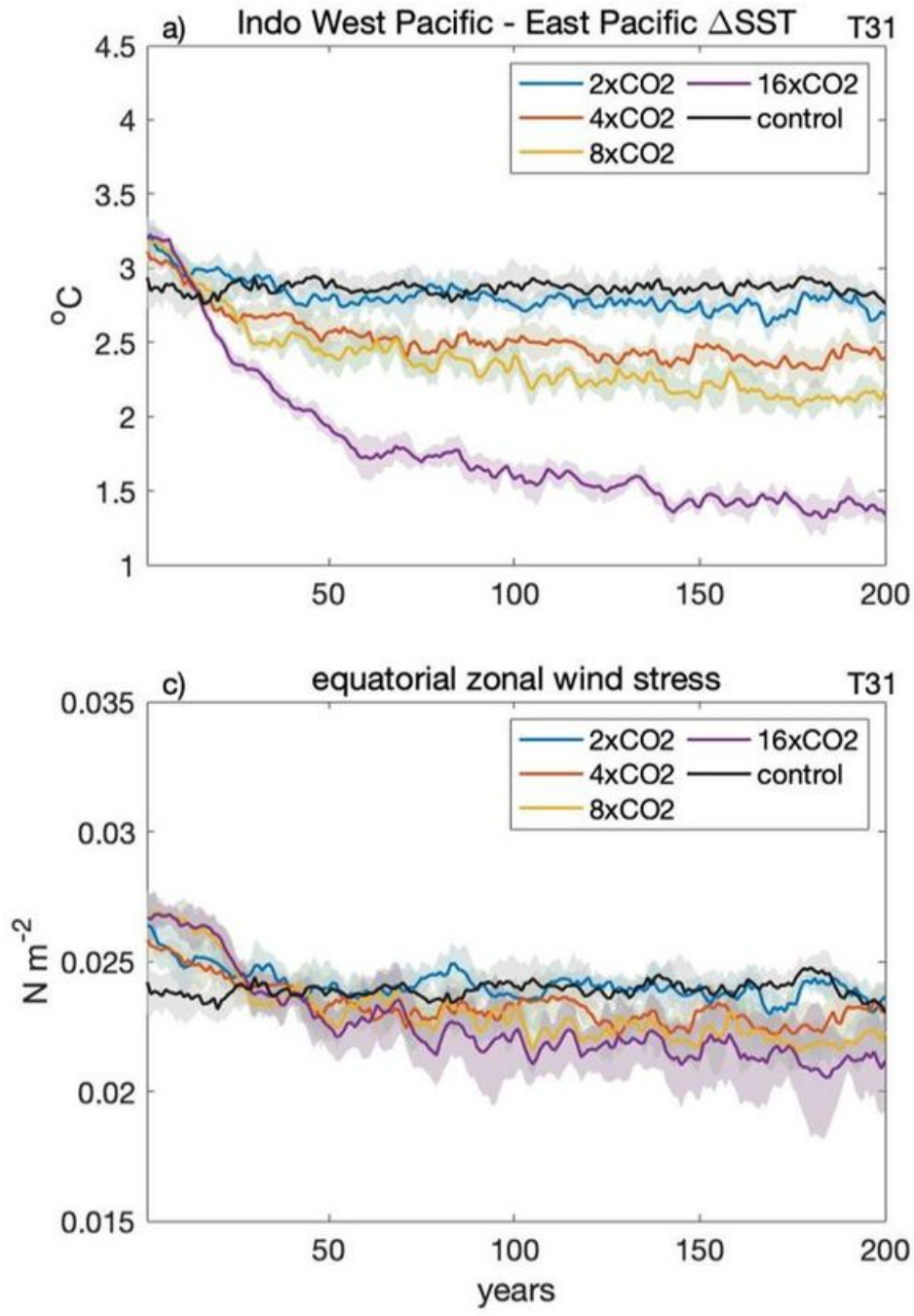

b) Indo West Pacific - East Pacific $\Delta S S T$
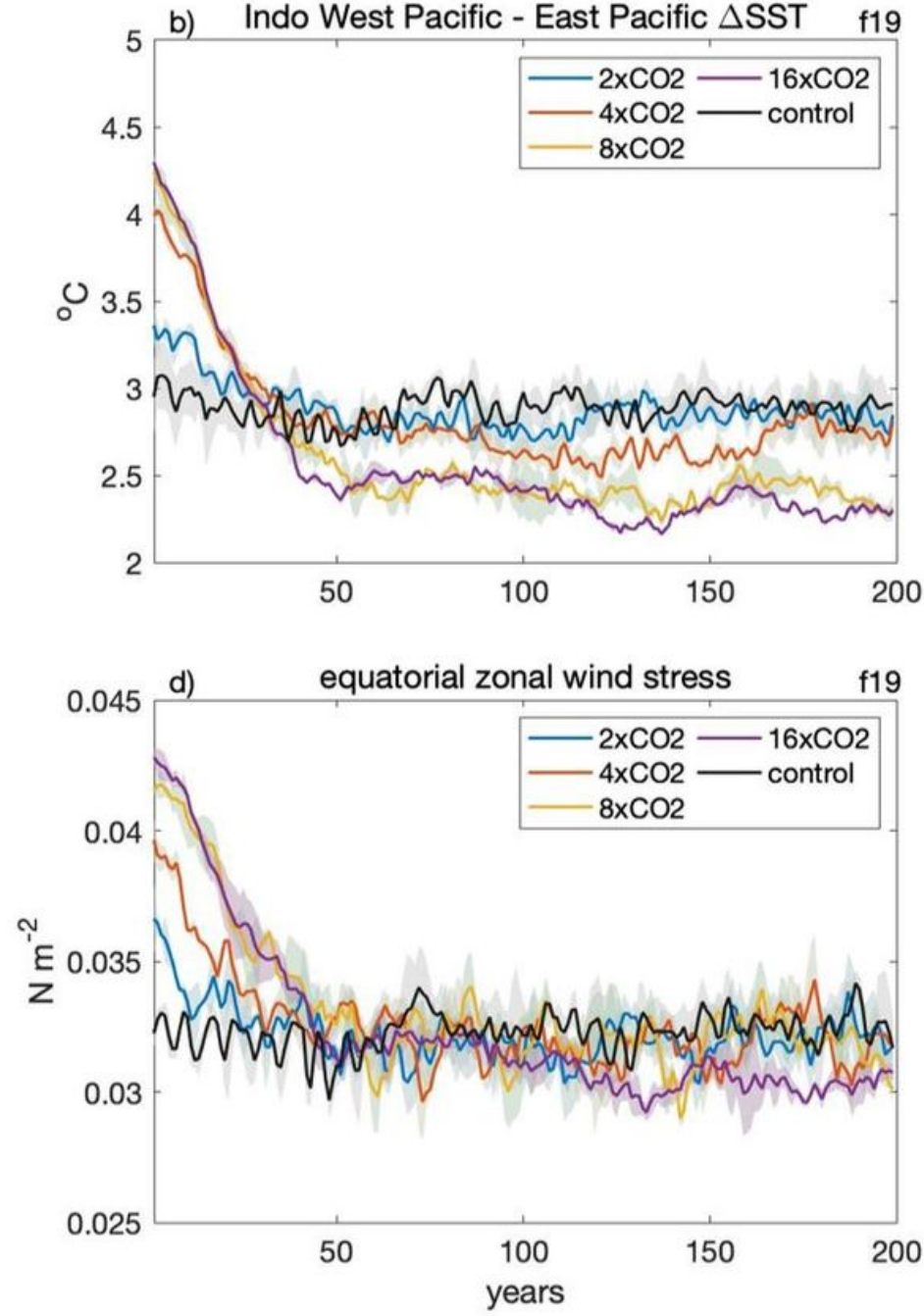

\section{Figure 1}

Variations in key variables in the control and abrupt $\mathrm{CO} 2$ increase experiments for two model configurations: (a), (b) the SST gradient between the Indo-Pacific warm pool ( $800 \mathrm{E}$ to $130 \mathrm{o}$ ) and the Central-Eastern Pacific $\left(180^{\circ} \mathrm{E}\right.$ to $\left.280^{\circ} \mathrm{E}\right)$; (c), (d) zonal wind stress integrated over the equatorial Pacific basin from $130^{\circ} \mathrm{E}$ to $280^{\circ} \mathrm{E}$. 10-year running means averaged between $5^{\circ} \mathrm{S}$ to $5^{\circ} \mathrm{N}$ and further averaged across 5 (T31) or 3 (f19) ensemble members are shown; shading indicates ensemble spread. The running mean window-size is adjusted to available data (5 years at endpoints). The left column corresponds to the T31 model; the right column to 19 . Note that the initial strengthening of the Walker cell is especially strong in the higher-resolution model (f19) and the equilibrium weakening of the Walker cell is more pronounced in the T31 model. The results from the T31 model in Figs. 1-3 also appear in Heede et al. (2020). 

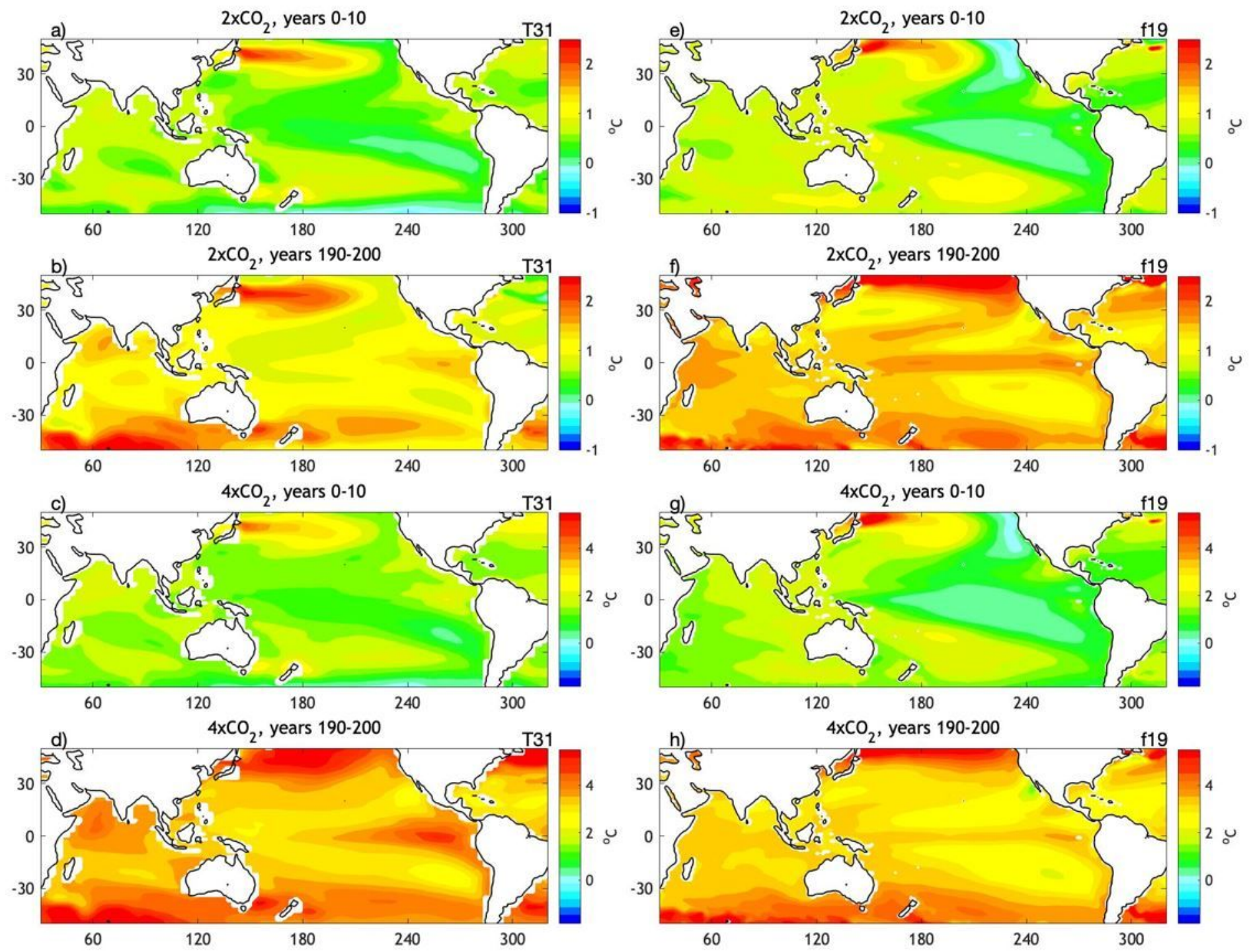

\section{Figure 2}

Examples of mean SST anomalies relative to the control, in ${ }^{\circ} \mathrm{C}$, for the $2 \times \mathrm{CO} 2$ and $4 \times \mathrm{xO} 2$ abrupt $\mathrm{CO} 2$-rise experiments. Left: the T31 model. Right: the f19 model. The top and third rows, i.e. panels (a), (c), (e), and (g), show averages for the first 10 years of each simulation. The second and bottom rows, i.e. panels (b), (d), (f), (h), are averaged for years 190-200. Ensemble means are used. Note that different scales are used for temperature in the two bottom versus two top rows. Note: The designations employed and the presentation of the material on this map do not imply the expression of any opinion whatsoever on the part of Research Square concerning the legal status of any country, territory, city or area or of its authorities, or concerning the delimitation of its frontiers or boundaries. This map has been provided by the authors. 

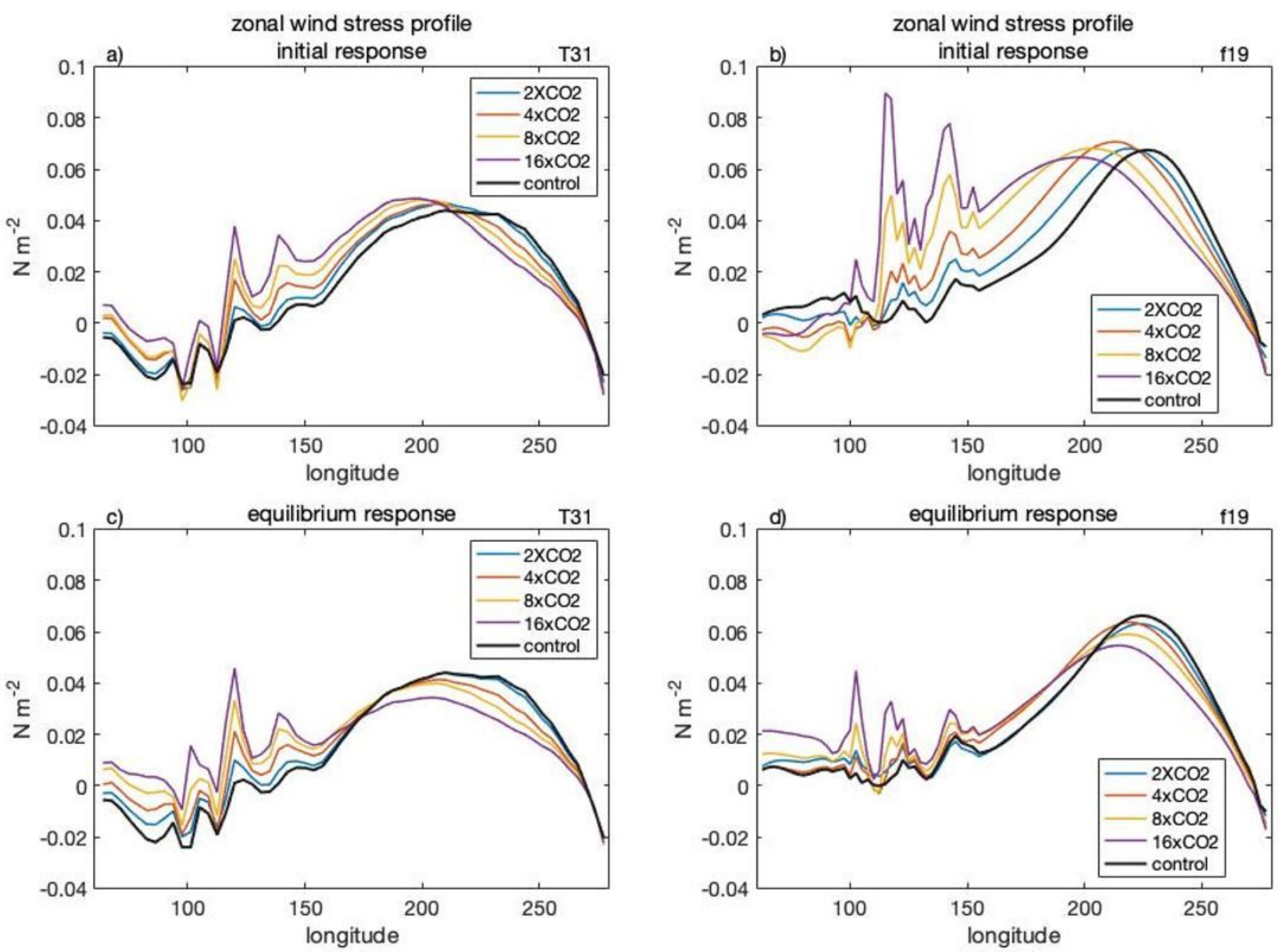

\section{Figure 3}

Mean zonal wind stress profiles along the equator for each $\mathrm{CO} 2$ perturbation experiment and the control experiment. Left: the T31 model. Right: the f19 model. The top row, panels (a) and (c), shows the initial response averaged over the first 10 years. The bottom row, panels (b) and (d), shows the equilibrium response averaged between the years 190-200 of the simulation. Ensemble means, further averaged between $5^{\circ} \mathrm{S}-5^{\circ} \mathrm{N}$, are used. Positive values indicate easterly winds. 

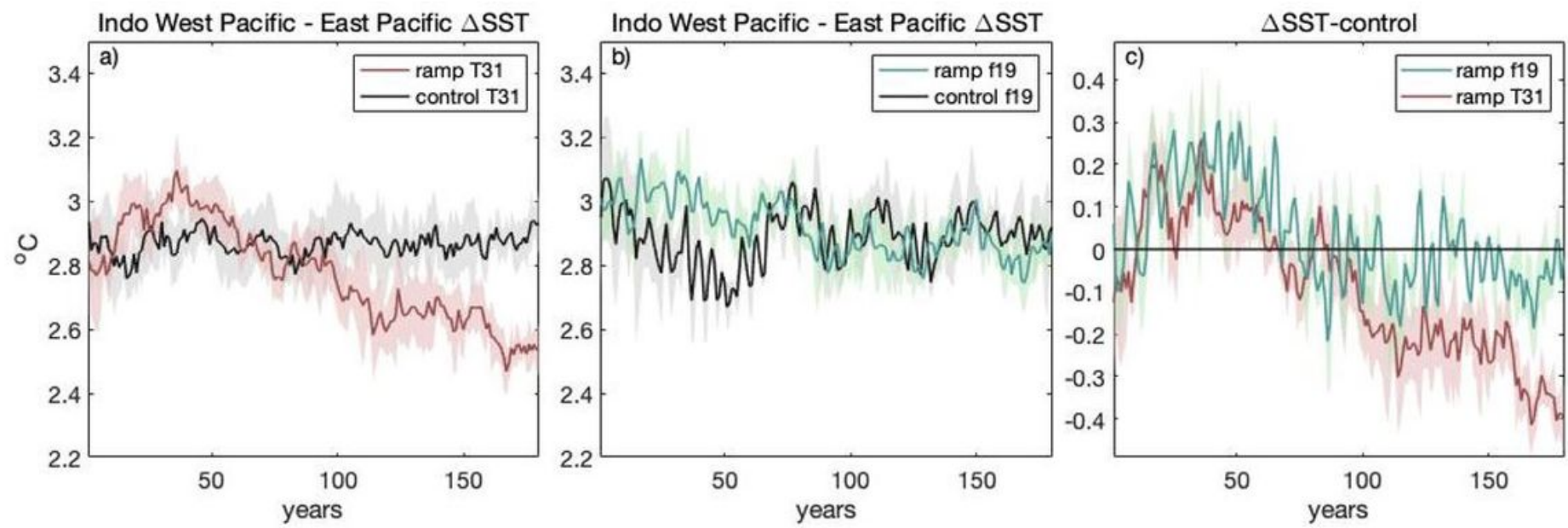

Figure 4

Evolution of the SST gradient, USST, between the Indo-Pacific warm pool ( $800 \mathrm{E}$ to $130 \mathrm{o}$ E) and the Central-Eastern Pacific $\left(180^{\circ} \mathrm{E}\right.$ to $\left.280^{\circ} \mathrm{E}\right)$ in ramped-CO2 simulations and the control experiment for (a) the T31 and (b) f19 models. Panel (c) shows anomalies in this SST gradient relative to the control for each model. The ramp experiments are conducted by linearly increasing $\mathrm{CO} 2$ from the pre-industrial level $(280 \mathrm{ppm})$ to $4 \times \mathrm{xCO} 2(1120 \mathrm{ppm})$ over 200 years. 10-year running means averaged between $5^{\circ} \mathrm{S}$ to $5^{\circ} \mathrm{N}$ and further averaged across 5 (T31) or 3 (f19) ensemble members are shown; shading indicates ensemble spread. The transient ocean thermostat response is evident in both models and persists for half to one century. T31 shows a weaker ocean thermostat, and a faster and more prominent transition to the weaker Walker regime.

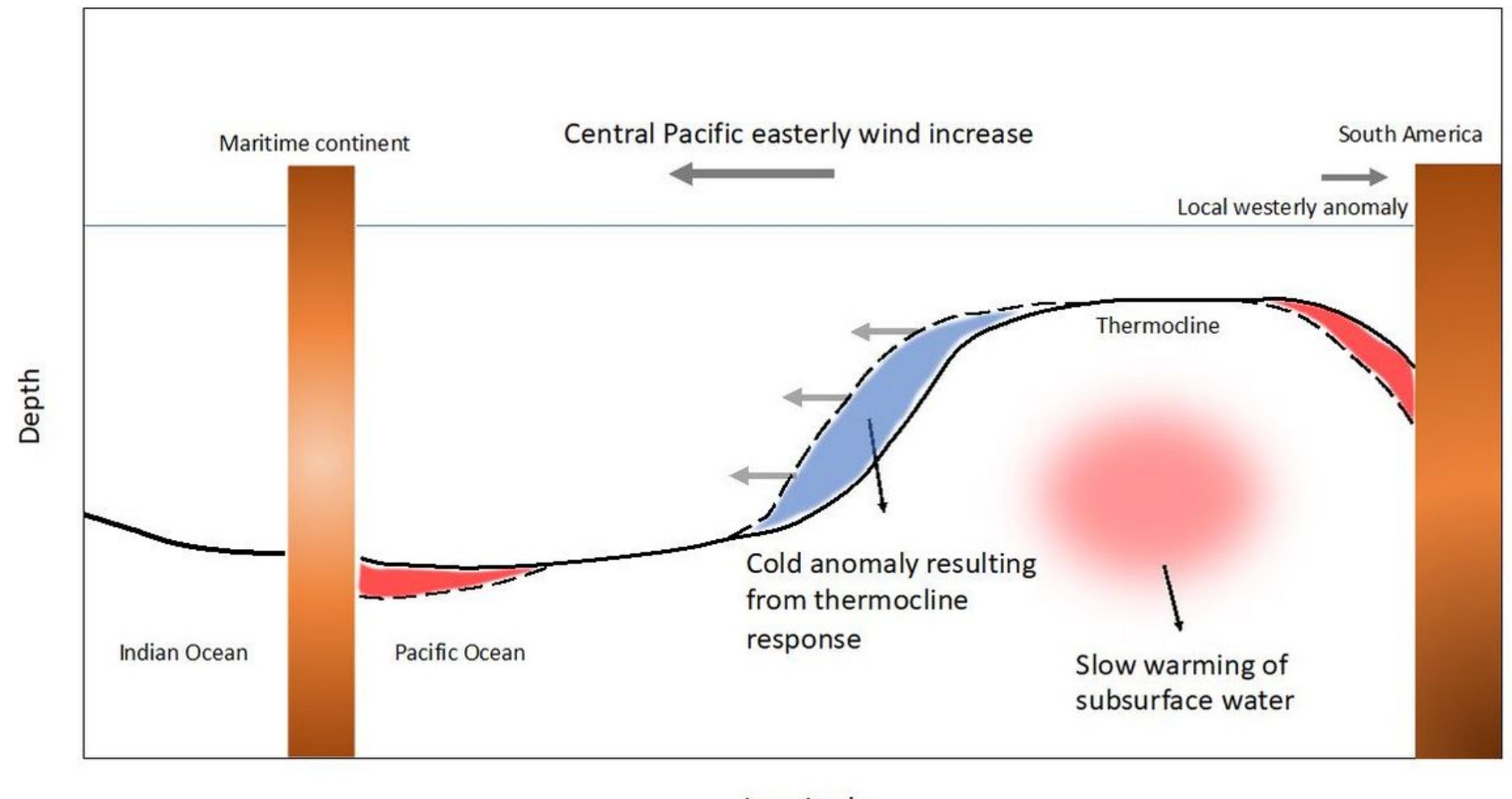

Longitude 


\section{Figure 5}

A schematic of the ocean response to atmospheric GHG forcing. Warming over the Indian ocean and the Maritime continent creates a westward shift of the Walker cell, which results in a westward shift of the thermocline with resultant transient cold anomalies in the central Pacific. Meanwhile, local westerly anomalies in the far east Pacific causes a depression of thermocline close to South America. The system gradually transitions to equilibrium response with the warming of subsurface waters due to the weakening of the subtropical cells and the warming of extra-tropical waters feeding the equatorial upwelling in the eastern equatorial Pacific.
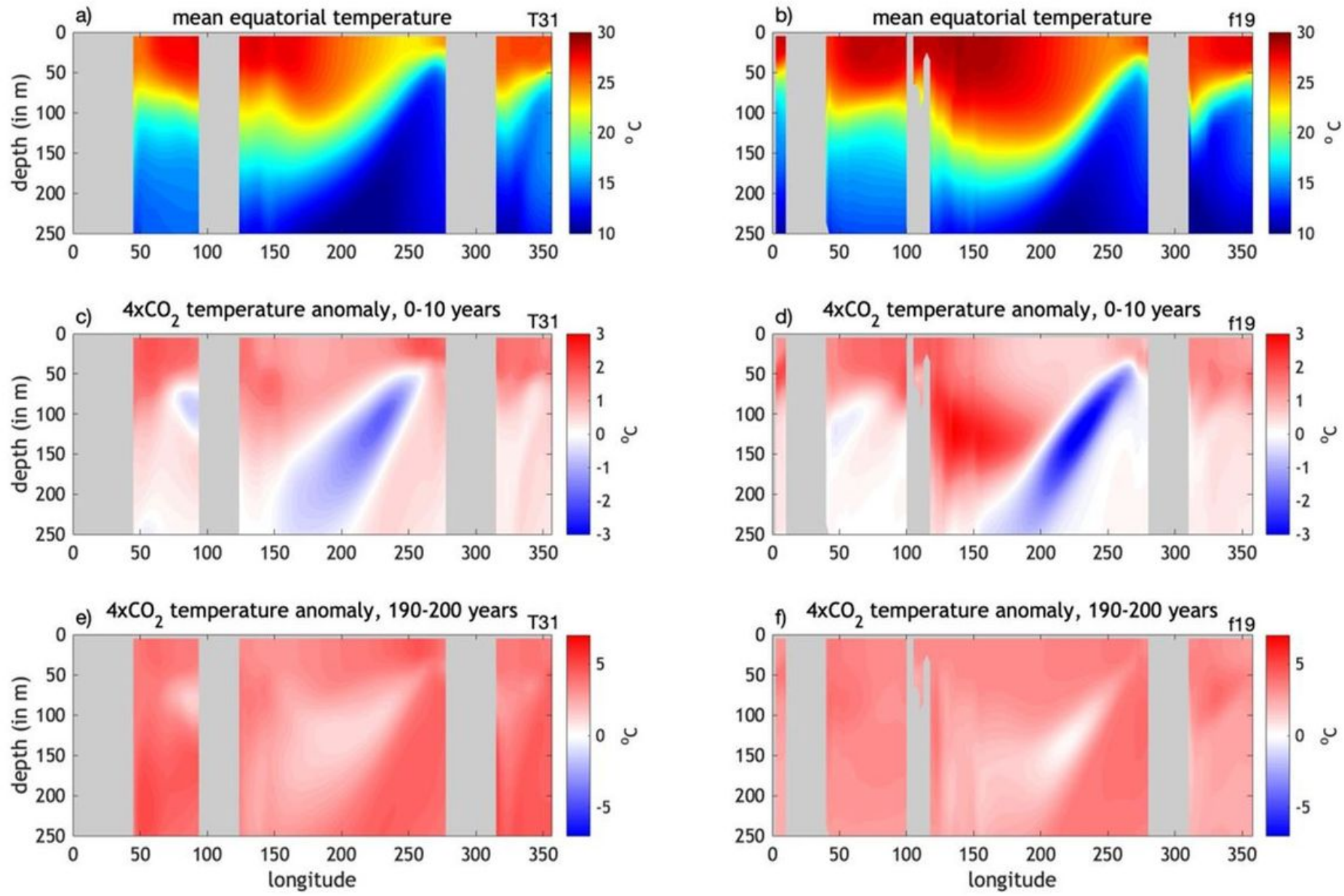

\section{Figure 6}

(Top) mean temperature in the control experiments and (middle, bottom) temperature anomalies relative to the control in the upper ocean in the abrupt 4xCO2 experiments. Panels (c) and (d): year 1-10 average; panels (e) and (f): year 190-200 average. The plot illustrates the initial thermocline response, with a cold anomaly in the central and eastern Pacific due to the shoaling of the thermocline caused by the westward shift of easterly winds, and then the gradual warming of subsurface waters. Left: the T31 model. Right: the f19 model. Ensemble-means are used. 

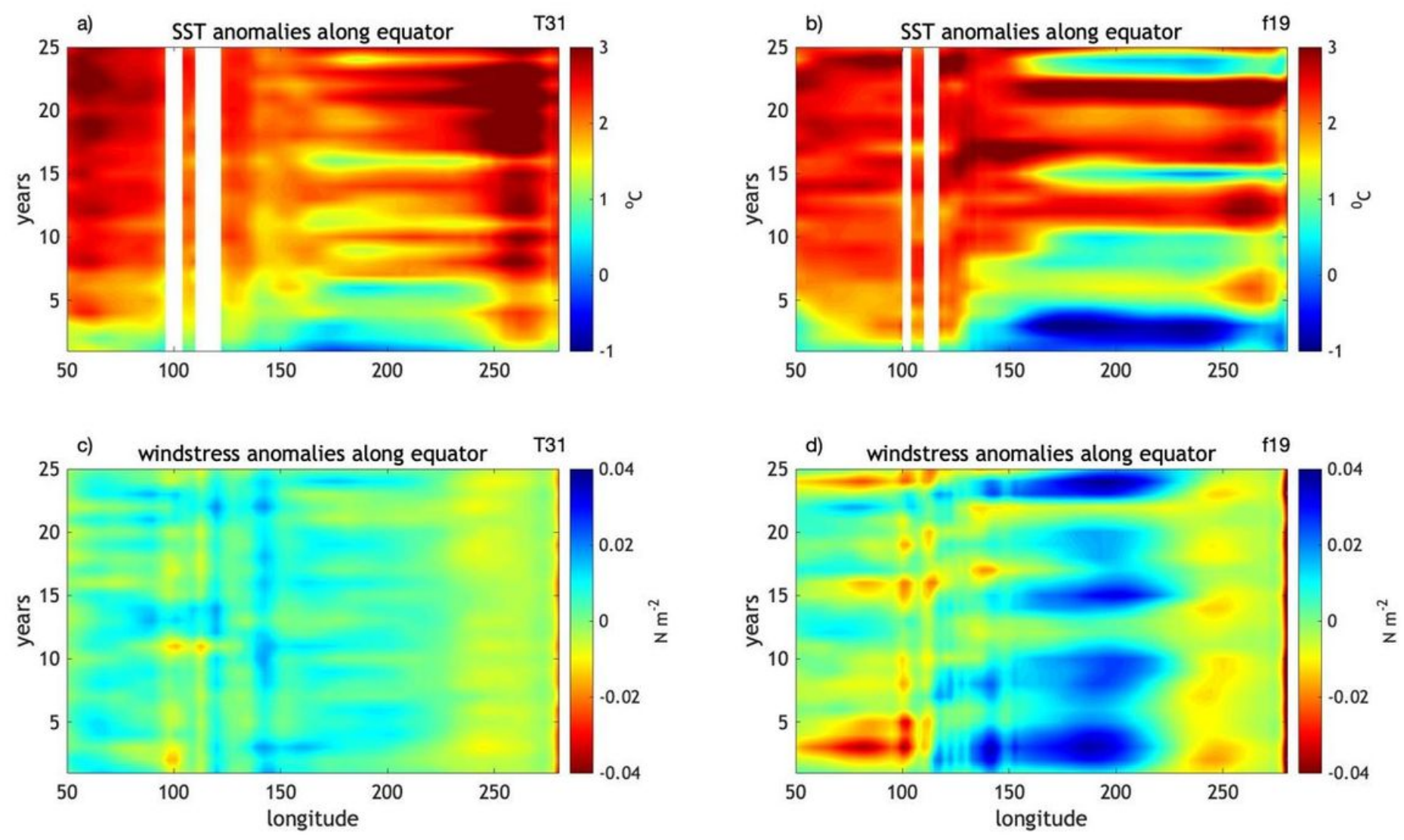

Figure 7

Hovmöller diagrams showing the annual-mean changes in (a),(b) SST and (c),(d) zonal wind stress relative to the control experiment along equator averaged from $5 \circ \mathrm{S}$ to $5 \circ \mathrm{N}$ for the first 25 years of abrupt 4xCO2 experiments. 3 ensemble members for each model are used. Note the initial strengthening of the Walker circulation as part of the thermostat response especially pronounced in the f19 model. This strengthening is consistent with a strong Bjerknes feedback operating in f19 as an anomalously strong SST gradient between the Indo-Pacific warm pool and the central/eastern equatorial Pacific co-develops with strong easterly wind stress anomalies. 

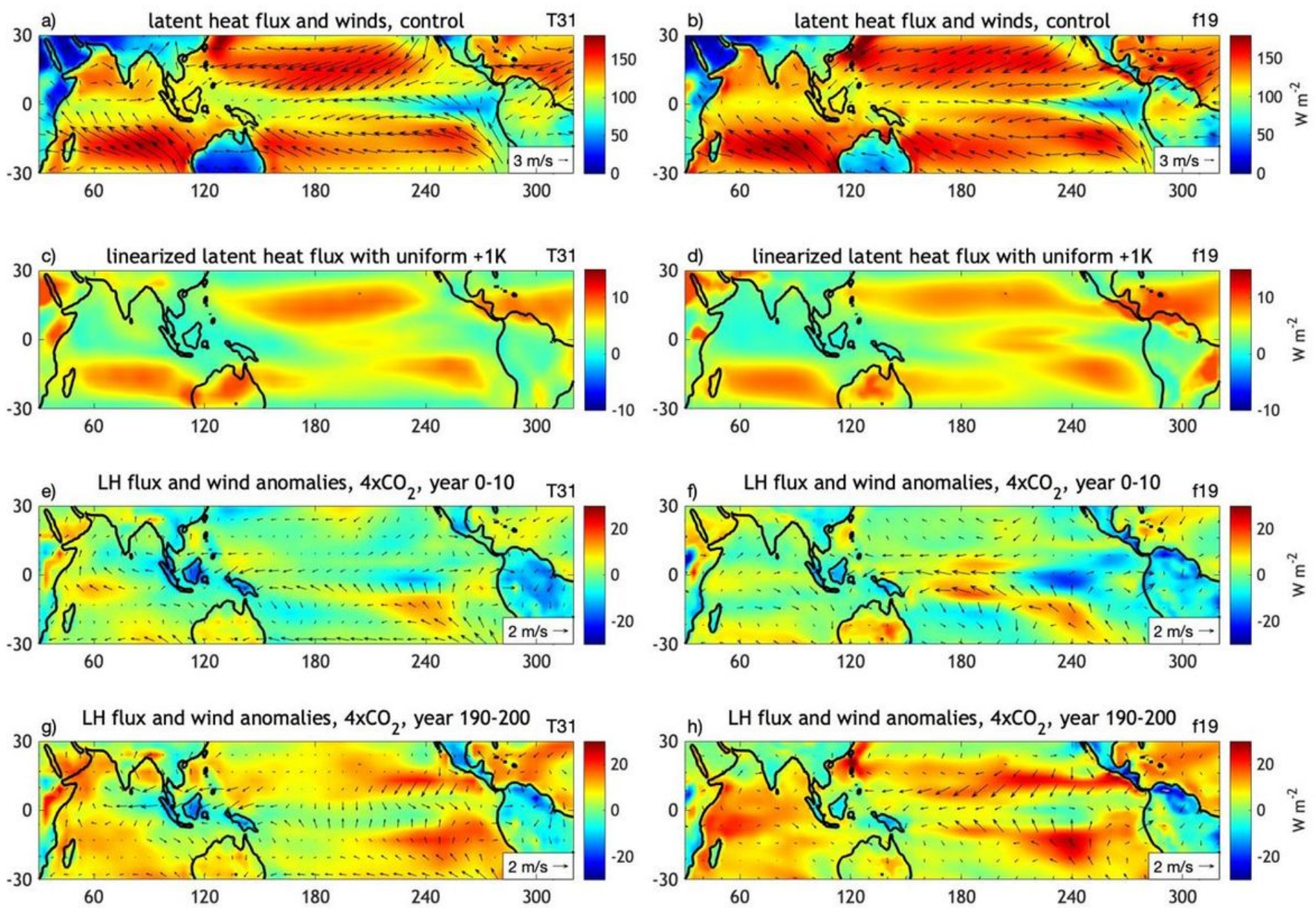

Figure 8

(a),(b) Mean latent heat (LH) fluxes (colors, in W/m2) and surface winds (arrows) in the control experiments. (c),(d) Predicted linearized latent heat flux anomalies induced by a $1 \mathrm{~K}$ surface warming as computed from the mean state winds, SST and relative humidity (see main text). (e), (f), (g), (h) Surface latent heat flux anomalies in the fully coupled 4xCO2 experiments for the two models initially (years 1-10) and after 190 years (years 190-200). Left: the T31 model. Right: the f19 model. Note: The designations employed and the presentation of the material on this map do not imply the expression of any opinion whatsoever on the part of Research Square concerning the legal status of any country, territory, city or area or of its authorities, or concerning the delimitation of its frontiers or boundaries. This map has been provided by the authors. 


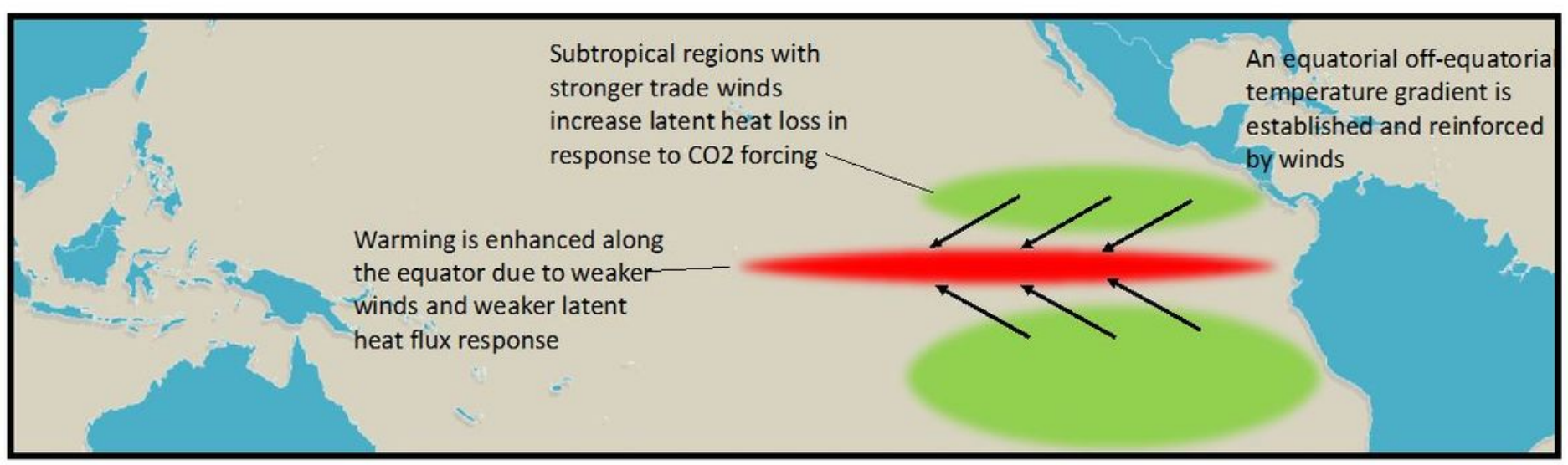

\section{Figure 9}

A schematic of the WES (wind-evaporation-SST) feedback linking off-equatorial and equatorial anomalies and amplifying the wind response along the equator. Initially, subtropical regions with stronger winds (green areas) balance more CO2-induced radiative forcing via latent heat fluxes than the equatorial region, which has generally weaker winds and colder SST (red area). This sets up a differential warming pattern in response to $\mathrm{CO}$-forcing where the equatorial region warms more than the subtropics. The meridional temperature gradient is in turn reinforced by stronger winds off-equator, which leads to additional latent heat release on both sides of equator. These winds may also affect the strength of the oceanic subtropical cells (STC) and hence the oceanic tunnel effect. Note that the strength of this WES feedback is typically stronger in the southern hemisphere (Zhao and Fedorov 2019). Note: The designations employed and the presentation of the material on this map do not imply the expression of any opinion whatsoever on the part of Research Square concerning the legal status of any country, territory, city or area or of its authorities, or concerning the delimitation of its frontiers or boundaries. This map has been provided by the authors. 

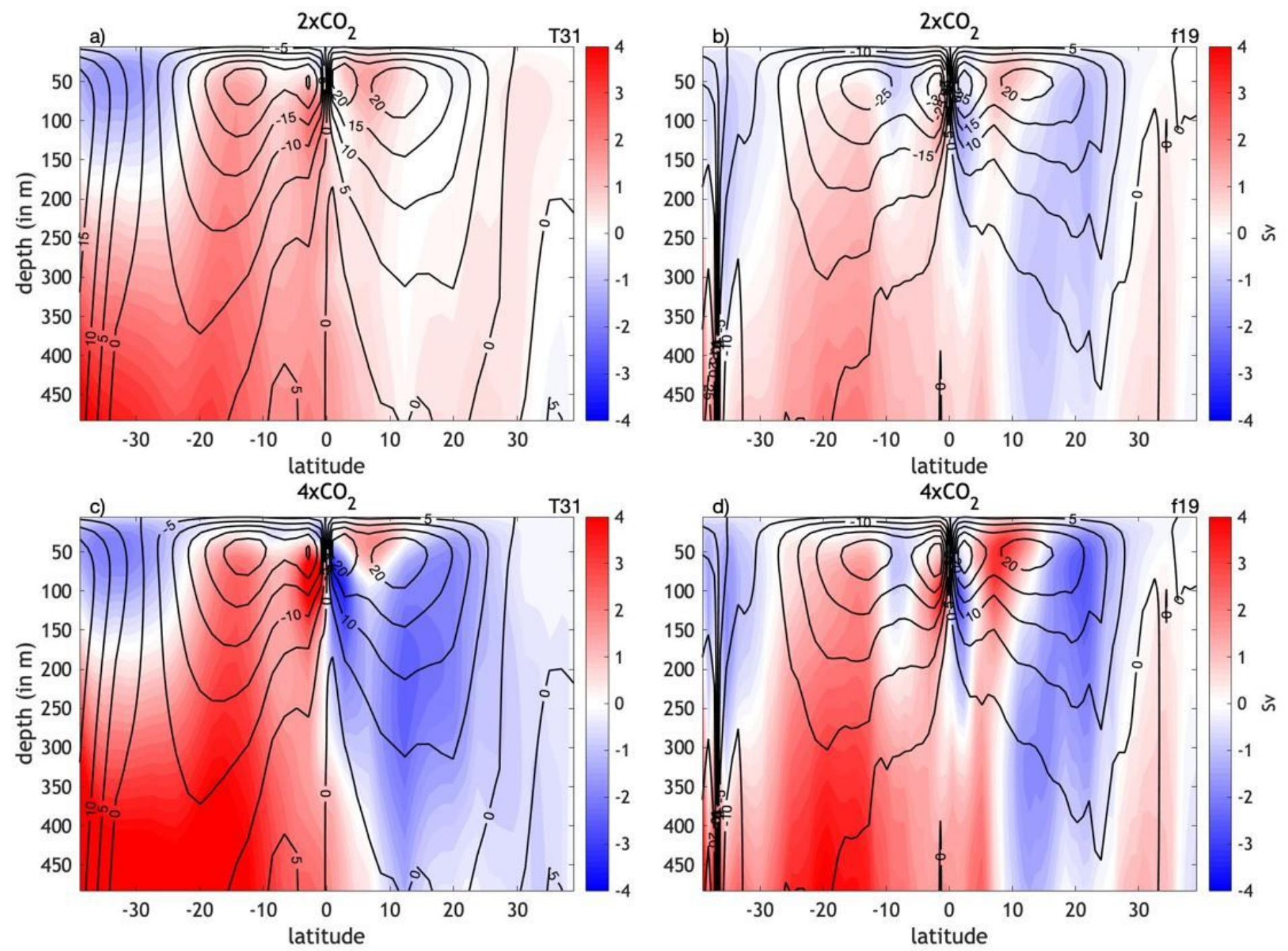

Figure 10

Anomalies (colors) and control mean values (contours) of the stream function (in units of Sv) in the IndoPacific for each CO2 experiment. Left: the T31 model; right: the f19 model. A time average across 400 years is used. The T31 plots show a substantial weakening of the upper $300 \mathrm{~m}$ meridional overturning within the northern subtropical cells (STC) while the southern cell becomes slightly stronger. The f19 plots show a strengthening but narrowing of the northern hemisphere STC with stronger circulation between 0 oand $150 \mathrm{~N}$. The results from the T31 model also appear in Heede et al. (2020). Temporal changes in the STCs are further highlighted in Fig. 11. 

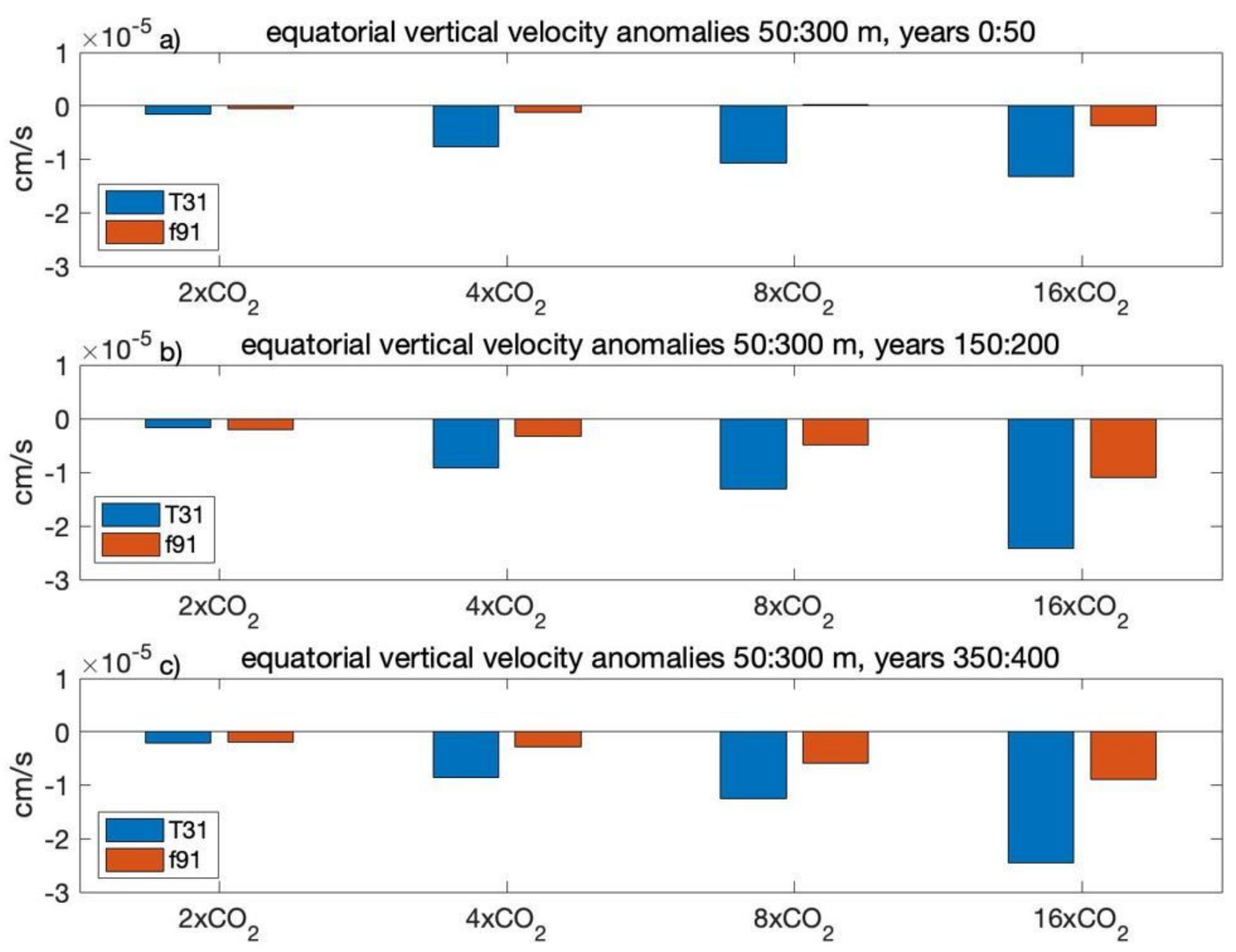

\section{Figure 11}

Changes in the vertical velocity averaged over the equatorial band in the Pacific ocean below the mixed layer for (a) years 0-50, (b) years 150-200, (c) years 350:400 in each of the abrupt CO2 increase scenarios. Blue is the T31 model and red is the f19 model. Velocity is averaged between 50 and $300 \mathrm{~m}$, west to east $150^{\circ}$ to $280^{\circ} \mathrm{E}$, and between $5^{\circ} \mathrm{S}$ to $5^{\circ} \mathrm{N}$. This broad averaging allows tracking the slowdown of the STCs. Ensemble means are used. Changes are relative to the control experiment. Note the weakening of STCs that starts in the first decades of the perturbation experiments but becomes progressively stronger later on. The weakening is greater for the T31 model. 

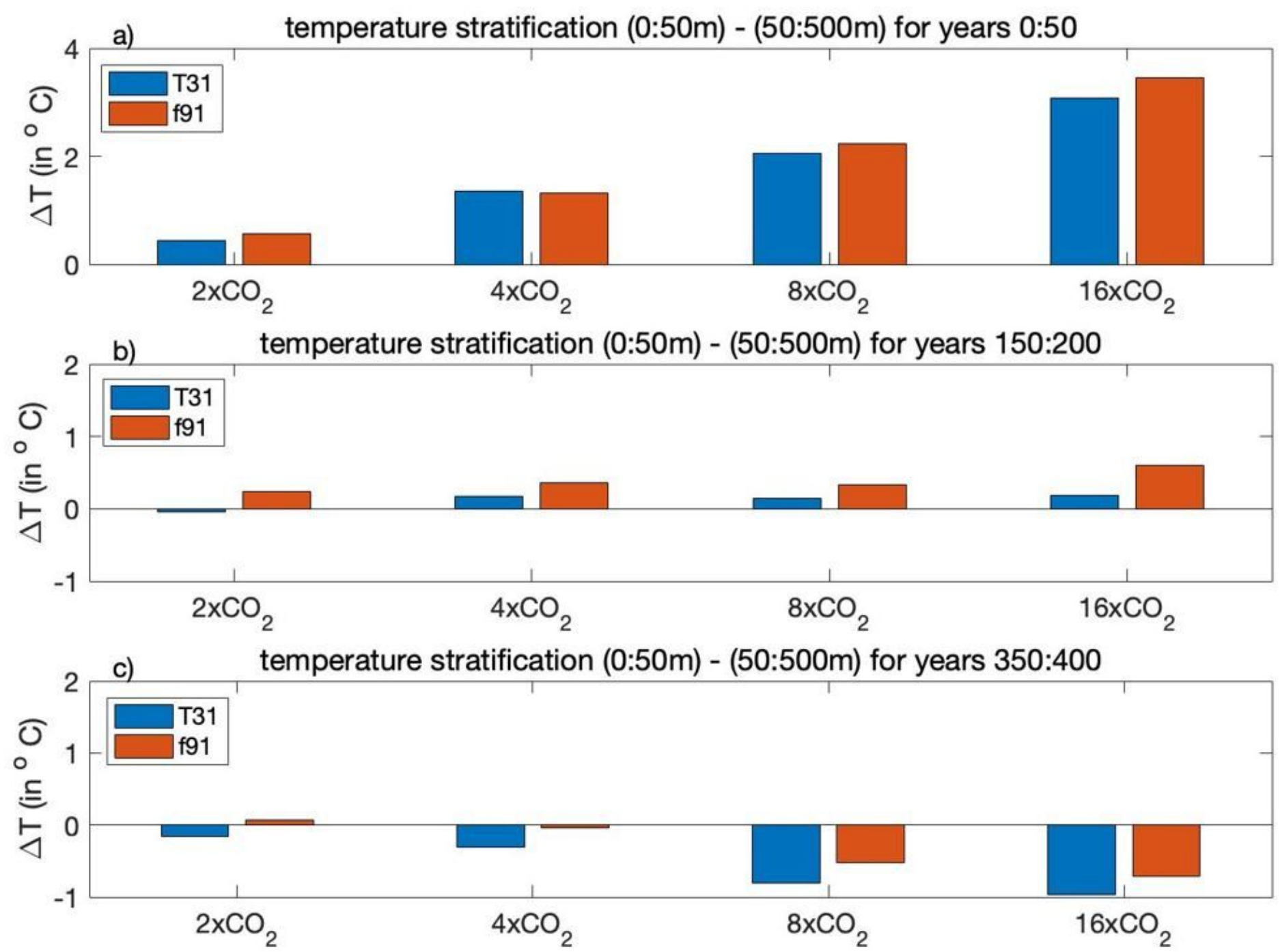

Figure 12

As in Fig. 11 but for changes in the mean upper-ocean temperature stratification. The temperature stratification is defined here as the difference between the mixed layer $(0-50 \mathrm{~m})$ and the upper ocean below the mixed layer (50-500m), averaged west to east $150^{\circ}$ to $280^{\circ} \mathrm{E}$, and between $5^{\circ} \mathrm{S}$ to $5^{\circ} \mathrm{N}$. This definition allows integrating over local changes in stratification due to wind-induced changes in the thermocline slope (see Fig. 6). Note the strong initial increase in stratification followed by a gradual reduction indicative of the ocean tunnel effect. 


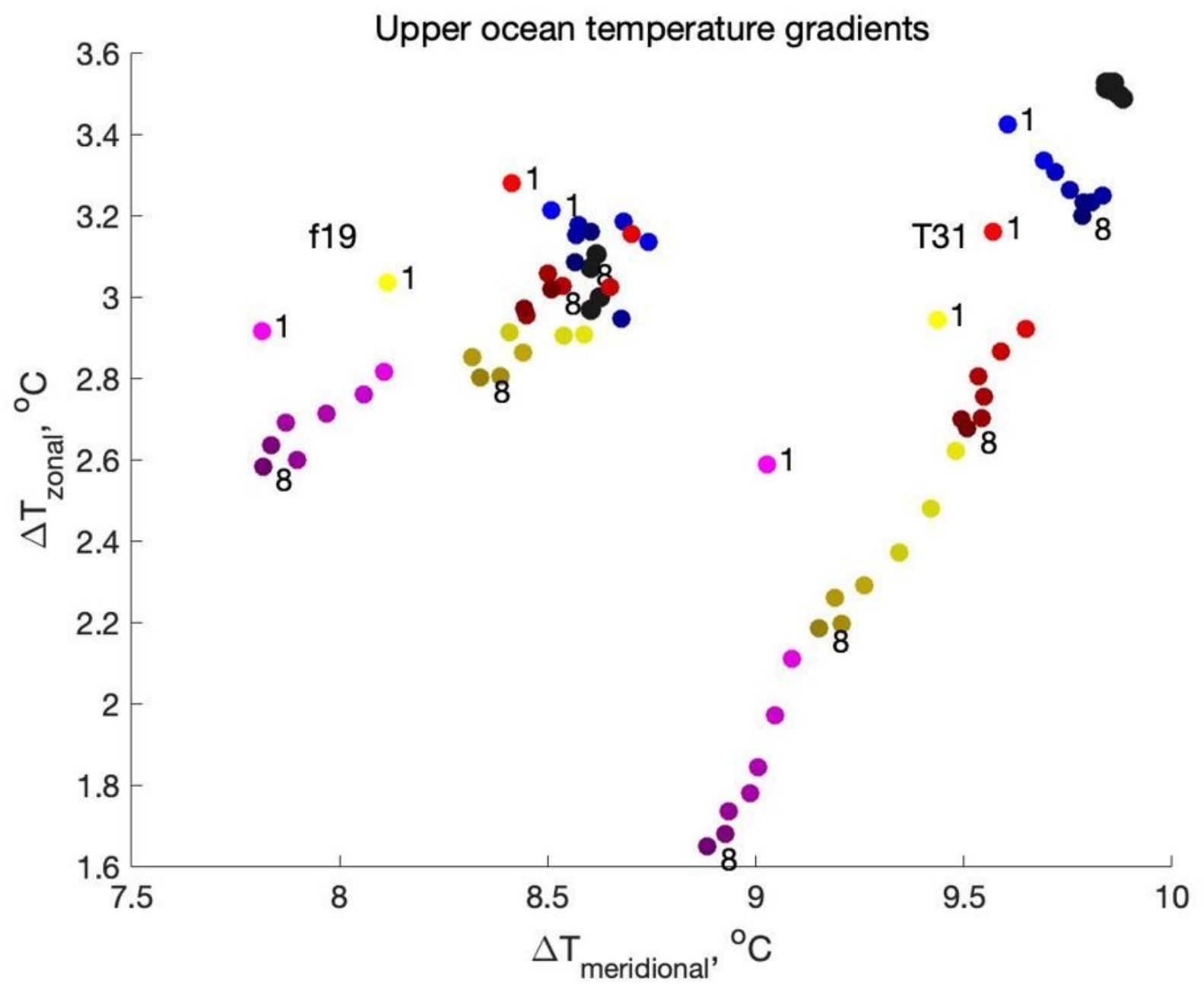

Figure 13

The zonal temperature gradient plotted against the meridional temperature gradient in the Pacific upperocean (in ${ }^{\circ} \mathrm{C}$ ) for the two models. Mean values over the upper $50 \mathrm{~m}$ are shown. Dots represent 50 -year averages from each simulation: color darkness represents progression in time. The first 50 years are denoted with 1 and the last 50 years (350-400 years) are denoted with 8. Each CO2 scenario is plotted in a different color, consistent with figure 1 . Black $=$ control simulation, blue $=2 \times \mathrm{CO} 2$, red $/ \mathrm{brown}=4 \times \mathrm{CO} 2$, yellow $=8 \times \mathrm{CO} 2$, pink/purple $=16 \times \mathrm{CO} 2$. The temperature gradients are defined in the methods section. The two big clusters of dots correspond to the two models considered. The results for the T31 model first appeared in Heede et al. (2020). That the data within each cluster eventually fall roughly onto one line connecting the meridional and zonal temperature gradients points to the importance of the ocean tunnel for the quasi-equilibrium response (Fedorov et al. 2015), especially for the T31 model and higher magnitudes of $\mathrm{CO} 2$. 